Article

\title{
Comparative Analysis of the Composition and Active Property Evaluation of Certain Essential Oils to Assess their Potential Applications in Active Food Packaging
}

\author{
Cornelia Vasile ${ }^{1, *}$, Morten Sivertsvik ${ }^{2, *}$, Amalia Carmen Mitelut ${ }^{3}$, Mihai Adrian Brebu ${ }^{1}$, \\ Elena Stoleru ${ }^{1}$, Jan Thomas Rosnes ${ }^{2}$, Elisabeta Elena Tănase ${ }^{3}$, Waqas Khan ${ }^{4}$, Daniela Pamfil ${ }^{1}$, \\ Călina Petruţa Cornea ${ }^{3}$, Anamaria Irimia ${ }^{1}$ and Mona Elena Popa ${ }^{3}$ \\ 1 Physical Chemistry of Polymers Department, "Petru Poni" Institute of Macromolecular Chemistry \\ Romanian Academy, 41A, Gr. Ghica Voda Alley, Iasi 700487, Romania; bmihai@icmpp.ro (M.A.B.); \\ elena.paslaru@icmpp.ro (E.S.); pamfil.daniela@icmpp.ro (D.P.); anamaria.sdrobis@icmpp.ro (A.I.) \\ 2 Nofima AS, Department of Processing Technology, Muninbakken 9-13, Tromsø 9291, Norway; \\ thomas.rosnes@nofima.no \\ 3 Faculty of Biotechnology, University of Agronomic Sciences and Veterinary Medicine of Bucharest, \\ 59 Mărăşti Blvd, District 1, Bucharest 011464, Romania; amaliamitelut@yahoo.com (A.C.M.); \\ elena.eli.tanase@gmail.com (E.E.T.); pccornea@yahoo.com (C.P.C.); pandry2002@yahoo.com (M.E.P.) \\ 4 Department of Biological Chemistry, University of Stavanger, Stavanger 4036, Norway; \\ khanwaqas2006@gmail.com \\ * Correspondence: cvasile@icmpp.ro (C.V.); Morten.Sivertsvik@nofima.no (M.S.); \\ Tel.: +40-232-217-454 (C.V.); +47-5184-4637 or +47-9059-7998 (M.S.); Fax: +40-232-211-299 (C.V.)
}

Academic Editor: Jung Ho Je

Received: 28 October 2016; Accepted: 3 January 2017; Published: 7 January 2017

\begin{abstract}
The antifungal, antibacterial, and antioxidant activity of four commercial essential oils (EOs) (thyme, clove, rosemary, and tea tree) from Romanian production were studied in order to assess them as bioactive compounds for active food packaging applications. The chemical composition of the oils was determined with the Folin-Ciocâlteu method and gas chromatography coupled with mass spectrometry and flame ionization detectors, and it was found that they respect the AFNOR/ISO standard limits. The EOs were tested against three food spoilage fungiFusarium graminearum, Penicillium corylophilum, and Aspergillus brasiliensis-and three potential pathogenic food bacteria-Staphylococcus aureus, Escherichia coli, and Listeria monocytogenes-using the disc diffusion method. It was found that the EOs of thyme, clove, and tea tree can be used as antimicrobial agents against the tested fungi and bacteria, thyme having the highest inhibitory effect. Concerning antioxidant activity determined by 2,2-diphenyl-1-picrylhydrazyl (DPPH) and 2,2'-azino-bis 3-ethylbenzthiazoline-6-sulfonic acid (ABTS) methods, it has been established that the clove oil exhibits the highest activity because of its high phenolic content. Promising results were obtained by their incorporation into chitosan emulsions and films, which show potential for food packaging. Therefore, these essential oils could be suitable alternatives to chemical additives, satisfying the consumer demand for naturally preserved food products ensuring its safety.
\end{abstract}

Keywords: essential oils; antifungal; antimicrobial; antioxidant; spoilage fungi

\section{Introduction}

Consumers demand high quality foods with minimal changes in nutritional properties. A minimal amount of synthetic additives combined with a suitable packaging technology that retains or creates desirable food qualities or reduces undesirable changes in food due to microbial activity is therefore a 
goal of food manufacturers [1]. New processes must be designed to meet the required food product safety or shelf-life demands, and additional hurdles for microorganisms should be introduced. World Health Organization (WHO) reports [2] in recent years estimate that $30 \%$ of people in industrialized countries suffer from a food-borne disease each year. Reducing or eliminating food-borne pathogens via "green" consumerism concomitantly with low salt consumption to diminish the incidence of cardiovascular diseases is increasingly becoming a public health concern. On the other hand, antimicrobial resistance affects all areas of health, as many medicinal procedures are related to antibiotics [3].

Therefore, new methods and additives should be found to prolong service life and to improve the safety of foods. Recently, effective preventive measures and intelligent preservation methods have been put into place to reduce food spoilage, increase safety, and prolong food shelf-life. One of these methods is bioactive packaging by the use of natural compounds with multifunctional properties both to achieve the protection of food and to improve the health of consumers. The concern regarding safety issues of the synthetic antimicrobial agents has led to the use of essential oils (EOs), which represent eco-friendly alternatives to chemicals. Essential oils (also called volatile oils) are oily liquids obtained from plant materials (flowers, buds, seeds, leaves, twigs, bark, herbs, wood, fruits, and roots). Plant-derived essential oils are complex mixtures of natural volatile compounds resulting from the plant secondary metabolism and extracted from vegetable materials by expression (i.e., "cold pressing"), fermentation, enfleurage, or extraction, but the method of distillation with water or steam is the most commonly used for the commercial production of EOs. Essential oils contain important classes of compounds such as monoterpenes ( $\mathrm{C}_{10}$ hydrocarbons based on 2 isoprene units), phenylpropanoides ( $C_{6}$ aromatic compounds with $C_{3}$ side chains), sesquiterpenes $\left(C_{15}\right.$ hydrocarbons based on 3 isoprene units), diterpenes $\left(C_{20}\right)$, triterpenes $\left(C_{30}\right)$ and their oxygenated derivatives, and phenolic compounds (such as thymol and carvacrol). Due to their versatile content, essential oils constitute a rich source of biologically active compounds possessing antimicrobial, antibacterial, antifungal, antioxidant, antiviral, antimycotic, antitoxigenic, antiparasitic, antibiotic, and antiseptic properties and insecticidal activities; therefore, they are useful in a wide range of applications $[4,5]$.

Each of the above-mentioned constituents contributes to beneficial or adverse effects; therefore, it is very important to know as much as possible about the composition and properties of EOs, with each study bringing new highlights on the advantages and disadvantages they offer.

There are many studies on the characterization of volatile compound composition and the antimicrobial and antioxidant activities of various selected groups of essential oils. Bozin et al. characterized Lamiaceae species and the antimicrobial and antioxidant activities of the oils of Ocimum basilicum L., Origanum vulgare L., and Thymus vulgaris L. [6], and the chemical constituents of four populations of Piper aduncum L. from Distrito Federal, Brazil [7], were identified. Many other essential oils have been characterized, namely, sweet lime (Citrus limetta Risso) [8], Chenopodium ambrosioides, Philodendron bipinnatifidum [9], cinnamon oil, eucalyptus oil, lemongrass oil, peppermint oil, citronella oil, turpentine oil [10], citronella oil [11], Tithonia diversifolia (Hemsl.) A. Gray [12], O. basilicum L. from Italy [13], and Iranian geranium oil [14]. The composition of two species of mint (Mentha suaveolens Ehrh. and Mentha rotundifolia) grown in Orăştie-Romania has been comparatively examinated [15]. From the 21 plant essential oils (cinnamon, clove, geranium, lemon, lime, orange and rosemary, aniseed, eucalyptus, and camphor) tested against six bacterial species four Gram-negative bacteria (Escherichia coli, Klebsiella pneumoniae, Pseudomonas aeruginosa, and Proteus vulgaris) and two Gram-positive bacteria Bacillus subtilis and Staphylococcus aureus [16], 19 oils showed antibacterial activity.

Consumers are worried about the presence of chemical preservatives, which can lead to benzoic acid by the decarboxylating action of some spoilage microorganisms, and this is considered the cause of many carcinogenic and teratogenic attributes and residual toxicity. Therefore, the studies to find natural and socially acceptable preservatives receive increasing attention by screening the composition and the biological, antimicrobial, and antioxidant activities of plant extracts [17]. Essential oils can 
prevent fungal growth in food products, which may cause spoilage and result in a reduction in the quality and quantity of food (shelf-life). Most EOs applied directly onto food or in the vapor phase can reduce or stop the colony forming ability of molds. They are also regarded as safe (GRAS) and are accepted by the FDA and by consumers. By their potential antimicrobial/antifungal/antioxidant effects, EOs could be the answer to the current search for environmental solutions and to assuring the microbial safety of food products in active packaging applications $[18,19]$.

In this study, four essential oils, namely, thyme (Thymus vulgaris L.), clove (Eugenia caryophyllus from dried floral buds of Syzygium aromaticum), rosemary (Rosmarinus officinalis L.), and tea tree (Melaleuca alternifolia aetheroleum) obtained from Romanian production (Fares Co., Orăştie, Romania) are intent to be used as components in bioactive food packaging. Therefore, as a first step, it should be worthwhile to comparatively evaluate the composition and antimicrobial/antioxidant activity of these four EOs. Antifungal and antibacterial activity against three target food spoilage fungi (Aspergillus brasiliensis, Fusarium graminearum, and Penicillium corylophilum) and three potential pathogenic food bacteria (S. aureus, E. coli, and L. monocytogenes) have been evaluated. The minimum inhibitory concentration (MIC) concentration was established in each case. The antioxidant activity was determined, and the most efficient oil for each type of activity was established. Preliminary tests on the EO encapsulation into chitosan films and their antimicrobial activity against the spoilage of beef meat showed promising results, a detailed presentation for which will be provided in a future paper.

\section{Results and Discussion}

\subsection{Chemical Composition}

\subsubsection{Phenolic Content}

The phenolic content of extracts of many plants contributes significantly to their total antioxidant activity. The antioxidant feature of the investigated essential oils was determined by the phenolic compouds presence in their composition by the Folin-Ciocâlteu method [20].

The total concentration of phenolic compounds found in essential oil samples are presented in Table 1, and a decrease in phenolic content concentration in the following order was found: clove $>$ thyme $>$ tea tree $>$ rosemary. Excepting the rosemary oil, all oils were found to have different phenolic levels, ranging from 0.034 to $1.136 \mathrm{mg} \cdot \mathrm{GAE} / \mathrm{g}$. DW, which can play a vital role in the increase of food shelf-life. The clove oil has the highest content of phenolic compounds.

Table 1. Total phenolic content in the investigated essential oils.

\begin{tabular}{cc}
\hline Oil Type & Total Phenolic Content $(\mathrm{mg} \cdot \mathrm{GAE} / \mathrm{g} \cdot \mathrm{DW}){ }^{*}$ \\
\hline Thyme & 0.349 \\
Clove & 1.136 \\
Rosemary & 0.000 \\
Tea Tree & 0.034 \\
\hline${ }^{*} \mathrm{mg} \cdot \mathrm{GAE} / \mathrm{g} \cdot \mathrm{DW}(\mathrm{mg}$ of gallic acid equivalent per g dry weight).
\end{tabular}

\subsubsection{GC-MSD and GC-FID Analysis}

The composition (including both main components and those in low amount but with significant biological/therapeutic effects) of the essential oils varies depending on the geographical position, the plant's origin and species, harvest time, distillation/extraction procedure, etc. [17]. Additionally, the composition of the essential oils and consequently their biological/therapeutic activities depend on the combination and ratio of their numerous different components. Gas chromatography coupled with mass spectrometry (GC-MSD) and flame ionization (GC-FID) detectors was used to determine the quality and quantity of chemical compounds in the essential oils.

The chromatograms of studied essential oils are shown in Figures 1-4. 
The essential thyme oil contains especially thymol, p-cymene, $\gamma$-terpinene, linalol, isothymol (carvacrol/biosol), and $\beta$-myrcene-Figure 1 .

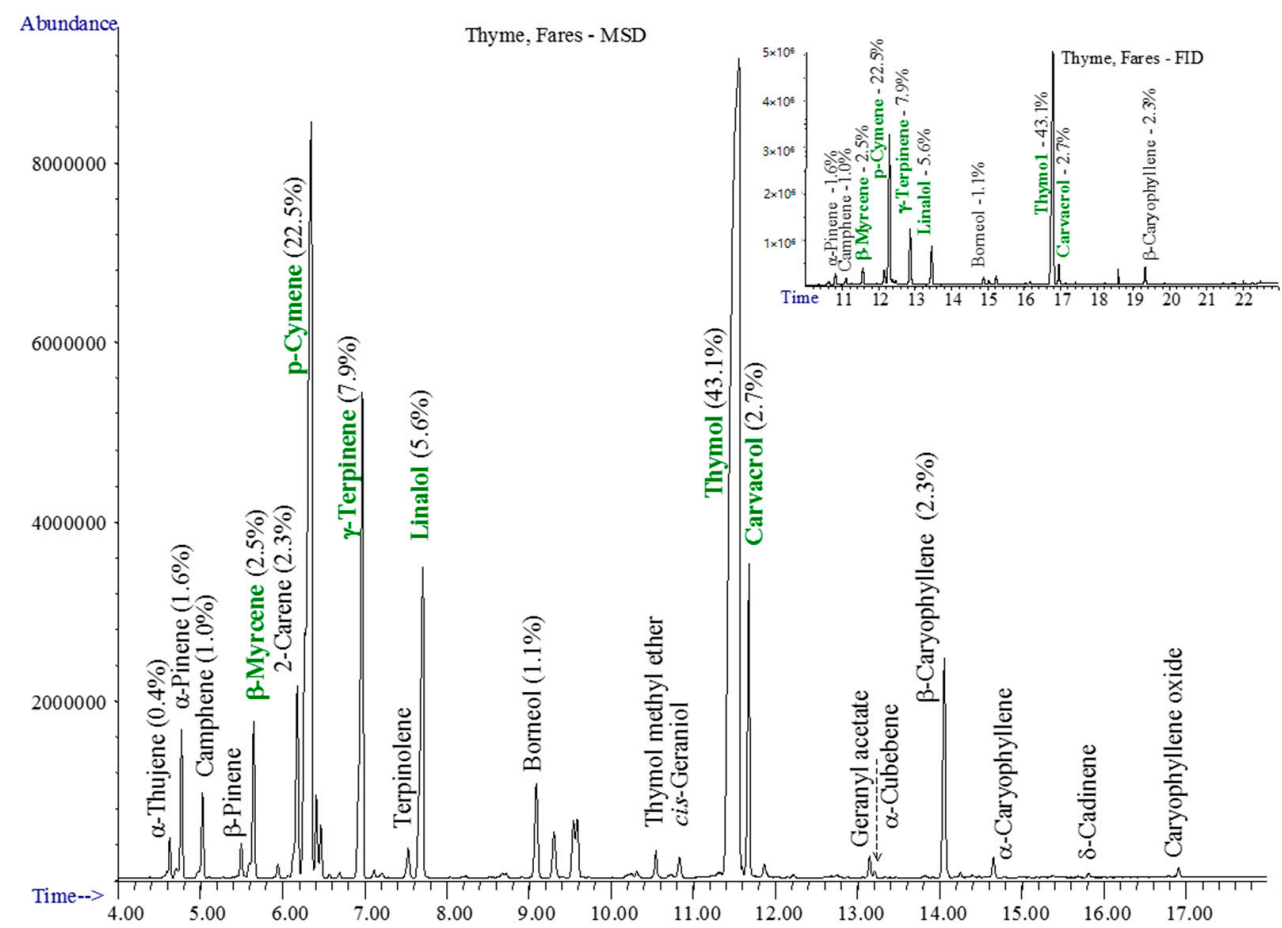

Figure 1. The GC-MSD and GC-FID (insert) chromatograms of thyme oil.

The clove essential oil had the simplest composition, based on eugenol/eugenol acetate and $\beta-/ \alpha$-caryophyllene, accompanied by several other sesquiterpenes-Figure 2.

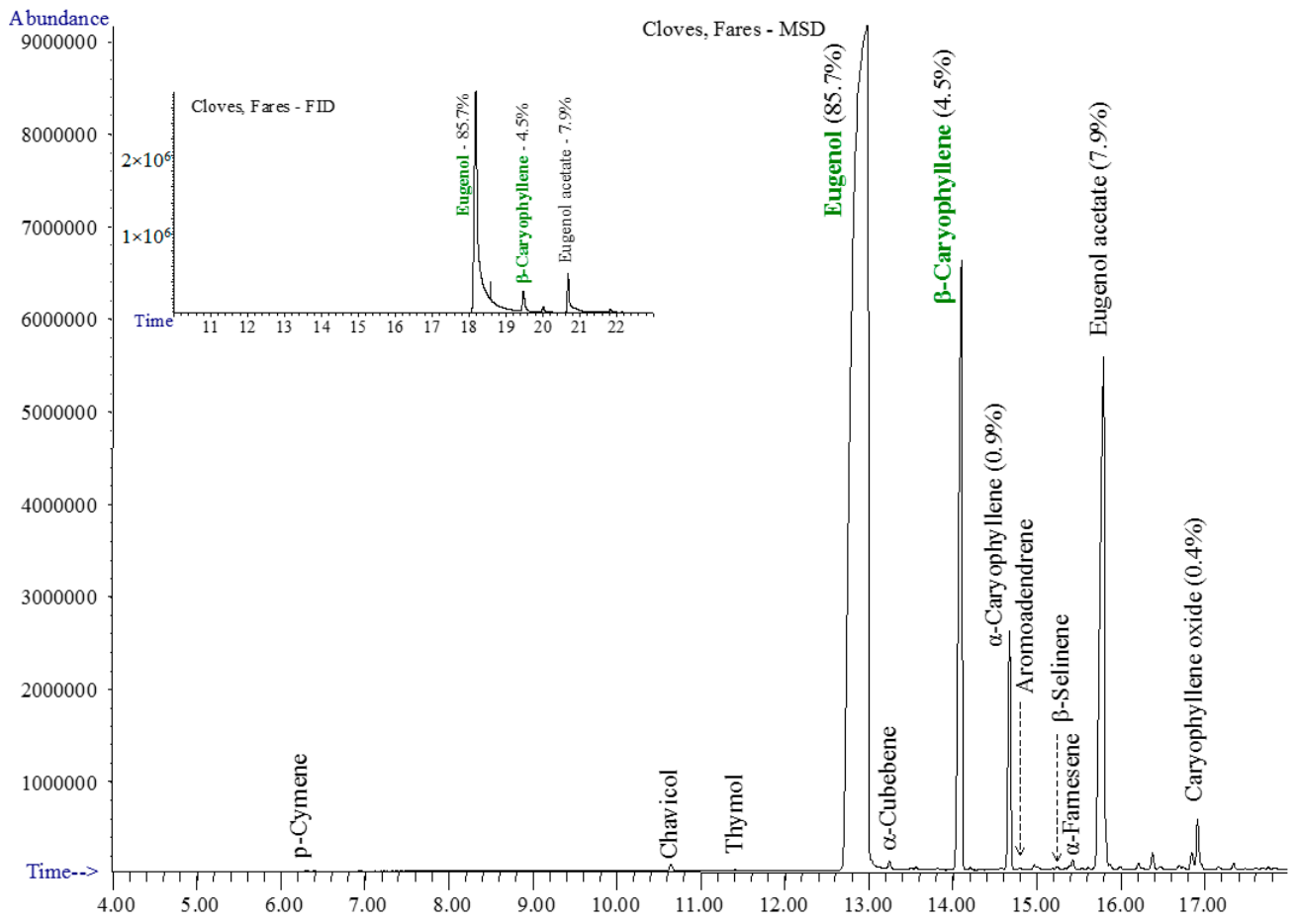

Figure 2. The GC-MSD and GC-FID (insert) chromatograms of clove oil. 
The rosemary oil is rich in light monoterpenes, containing mainly eucalyptol, camphor, $\alpha$-/ $\beta$-pinene, camphene, borneol, and limonene-Figure 3.

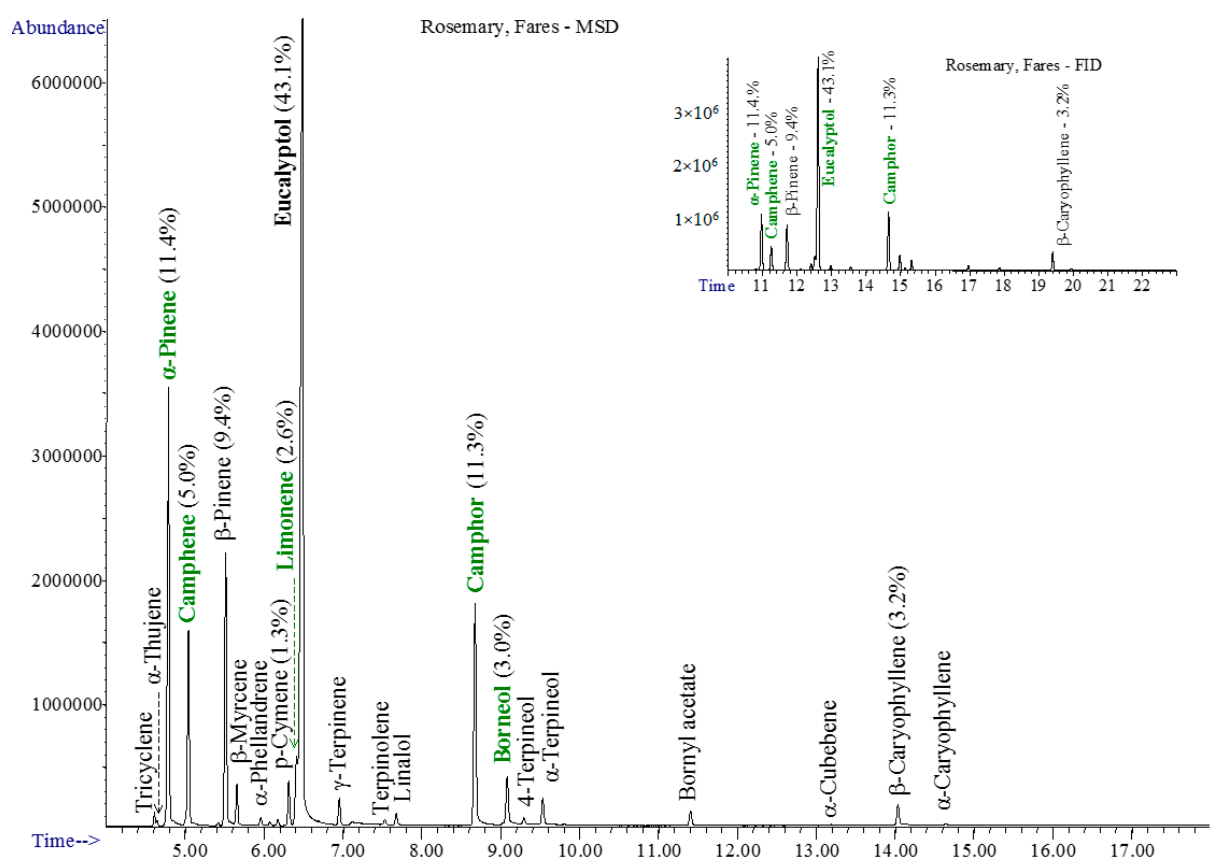

Figure 3. The GC-MSD and GC-FID (insert) chromatograms of rosemary oil.

The tea tree essential oil contained both light monoterpenes and numerous sesquiterpenes. The main compound is 4 -terpineol, followed by $\gamma$-terpinene, 2-carene, $\alpha$-terpineol, $\alpha$-terpinene, $\alpha$-pinene, o-cymene, limonene, $\beta$-caryophyllene, eucalyptol, and $\beta$-myrcene-Figure 4 . Standards ask for $\alpha$-terpinene ( $5 \%-13 \%)$, which was not found in our tee tree sample, instead 2-carene was found in high amounts of about $10 \%$. Aromadendrene and $\delta$-cadinene, mentioned by standards in amounts varying from traces up to $7 \%-8 \%$ were confirmed in the studied sample.

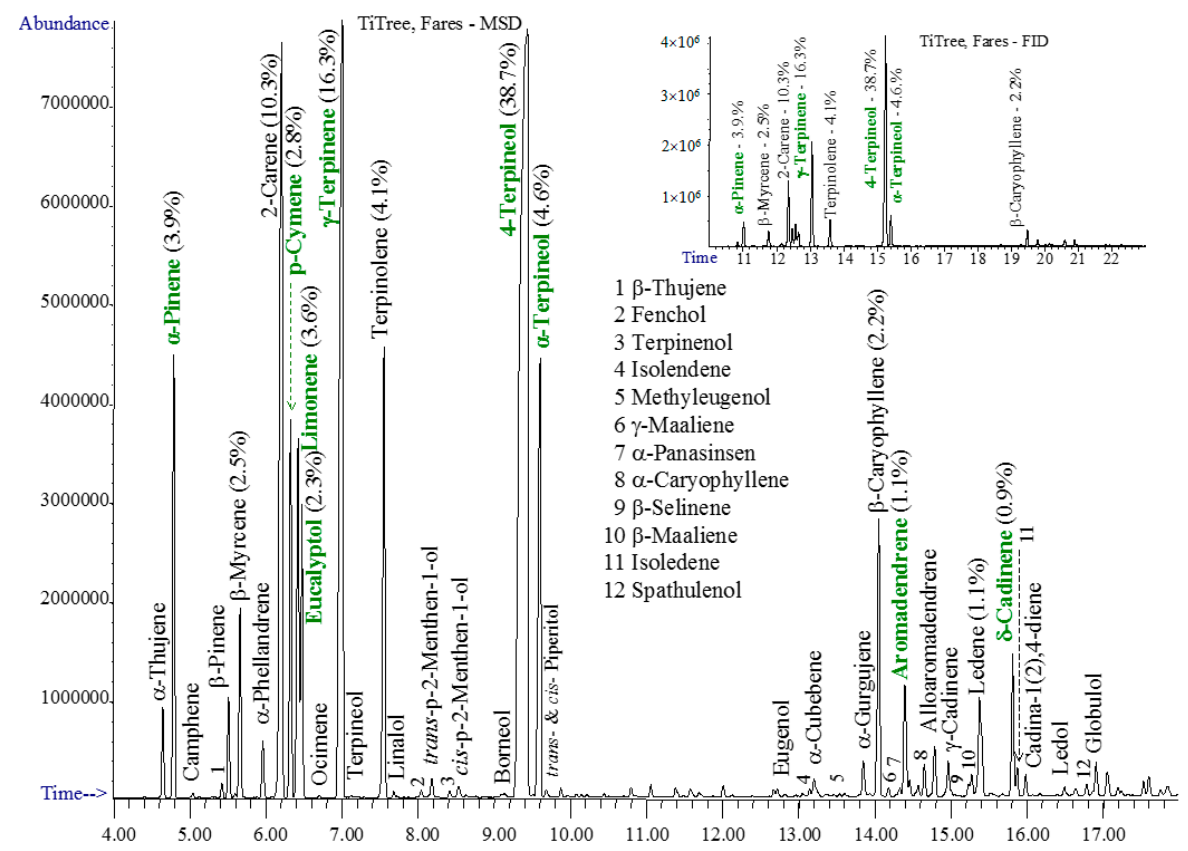

Figure 4. The GC-MSD and GC-FID (insert) chromatograms of tea tree oil. 
The main classes of compounds identified in the studied essential oils are presented in Table 2. Under the mentioned analysis parameters, only volatile compounds up to the level of sesquiterpenes were detected.

Table 2. The main classes of compounds found in the studied essential oils.

\begin{tabular}{cl}
\hline Class of Compounds & \multicolumn{1}{c}{ Main Compounds } \\
\hline $\begin{array}{c}\text { Monoterpenes } \\
\text { (C10 with } 2 \text { isoprene units })\end{array}$ & $\begin{array}{l}\text { Borneol, Camphene, Camphor, Carene, Carvol, Citral, p-Cymene, } \\
\text { Eucalyptol, Fenchone, Geraniol, Limonene, Linalol, Menthone, Myrcene, } \\
\text { Ocimene, Phellandrene, Piperitol, Terpinene, Thujene, Thymol }\end{array}$ \\
\hline $\begin{array}{c}\text { Phenylpropanoides } \\
\text { (C6 with C3 side chains })\end{array}$ & Apiole, Chavicol, Cinnamaldehyde, Estragole, Eugenol, Myristicin \\
\hline $\begin{array}{c}\text { Sesquiterpenes } \\
\text { (C15 with } 3 \text { isoprene units })\end{array}$ & $\begin{array}{l}\text { Amorphene, Aromoadendrene, Cadinene, Caryophyllene, Cubebene, } \\
\text { Elemene, Farnesene, Globulol, Gurgujene, Isolendene, Maaliene, } \\
\text { Panasinsen, Selinene, Spathulenol }\end{array}$ \\
\hline
\end{tabular}

Table 3 shows the quantitative composition (based on Gas Chromatographz with Flame Ioniyation Detector (GC-FID) of the analyzed essential oils. The GC-FID analysis was performed on several different samples obtained from the same company, i.e., Fares, Orăştie-Romania, and no relevant difference was found between them. The results are reproducible.

The composition of the four essential oils is within the limits of AFNOR (Association French Normalization Organization Regulation)/ISO standards [21-25], except for a few differences, which could be considered within the error limits of the analysis. Deviation in the composition from standard values may not interfere with the therapeutic properties of the essential oils; however, if oils respect the standard limits, it is safer to consider them usable according to the general practice.

Table 3. The composition of the selected commercial essential oils from the Fares Company, Romania, compared with AFNOR/ISO standards *.

\begin{tabular}{|c|c|c|c|c|}
\hline Chemical Compound & Thyme & Clove & Rosemary & Tea Tree \\
\hline ORAC $(\mu \mathrm{TE} / 100 \mathrm{~g})^{* *}$ & 15,960 & $1,078,700$ & 330 & \\
\hline$\alpha$-Thujene & 0.4 & & & \\
\hline$\alpha$-Pinene & 1.6 & & 11.4 & 3.9 \\
\hline Camphene & 1.0 & & 5.0 & \\
\hline$\beta$-Pinene & & & $9.4(<9)$ & \\
\hline$\beta$-Myrcene & 2.5 & & & 2.5 \\
\hline 2-Carene & 2.3 & & & 10.3 \\
\hline p-Cymene & 22.5 & & 1.3 & 2.8 \\
\hline Limonene & & & 2.6 & 3.6 \\
\hline Eucalyptol & & & 43.1 & 2.3 \\
\hline$\gamma$-Terpinene & 7.9 & & & 16.3 \\
\hline$\alpha$-Terpinene & & & & $4.1(>5)$ \\
\hline Linalol & 5.6 & & & \\
\hline Camphor & & & 11.3 & \\
\hline Borneol & 1.1 & & 3.0 & \\
\hline 4-Terpineol & & & & 38.7 \\
\hline$\alpha$-Terpineol & & & 1.8 & 4.6 \\
\hline Thymol & 43.1 & & & \\
\hline Carvacrol & 2.7 & & & \\
\hline Eugenol & & 85.7 & & \\
\hline$\beta$-Caryophyllene & 2.3 & 4.5 & 3.2 & 2.2 \\
\hline$\alpha$-Caryophyllene & & 0.9 & & \\
\hline Aromadendrene & & & & 1.1 \\
\hline Ledene & & & & 1.1 \\
\hline Eugenol acetate & & $7.9(>8)$ & & \\
\hline$\delta$-Cadinene & & & & 0.9 \\
\hline Caryophyllene oxide & & 0.4 & & \\
\hline
\end{tabular}

* The bold numbers in Table 3 indicate values within the limits of the standards; italic numbers are below the limits, while the underlined are over the limits, the bracket showing the closest limits in the standard. ** ORAC — oxygen radical absorption capacity; expressed as $\mu$ mol Trolox equivalent (TE) at $100 \mathrm{~g}$, accuracy of $\pm 5 \%$, as presented in the literature $[26,27]$. 
The ORAC index shows the antioxidant capacity of the oils. According to databases, the antioxidant capacity is highest for clove essential oil, followed at a high distance by thyme oil, while the antioxidant capacity for tea tree is smaller than those of other essential oils. These statements are in accordance with results obtained by the Folin-Ciocâlteu method.

Based on the gas chromatography analysis coupled with mass spectrometry and flame ionisation detectors, the commercial essential oils of thyme (Thymus vulgaris L.), clove (Eugenia caryophyllus), rosemary (Rosmarinus officinalis L.), and tea tree (Melaleuca alternifolia aetheroleum) were found to have compositions within the limits of the AFNOR/ISO standards.

Most of the obtained results related to the composition of the studied essential oils are in accordance with those found by other authors and constitute support for the explanation of their potential biological activity spectrum [28-44]. Thyme essential oil (TEO) is obtained from Thymus vulgaris $\mathrm{L}$. and exhibits antimicrobial effects due to its constituents. Omidbeygi et al. [28] found that the major compounds of TEO are thymol, carvacrol with similar chemical structures, linalool, and $\rho$-cymene $[28,29]$. The presence of thymol (2-Isopropyl-5-methylphenol) and carvacrol enhanced the TEO antimicrobial activity [30-32]. Clove essential oil (Caryophylli aetheroleum) (CEO) isolated from the dry floral buds of Syzygium aromaticum, belonging to the Myrtaceae family has been used for its antimicrobial activity. Goni [33], Shao [34], and Sebaaly [35] established that the CEO is composed mainly of phenylpropanoides such as eugenol, $\beta$-caryophyllene, and the eugenyl acetate [33-36].

Jiang et al. [37] found that the rosemary essential oil (Rosmarinus officinalis L.) (REO) can be used in the food industry as a flavoring agent and preservative because of its antimicrobial and antioxidant properties [37]. Among the terpenes found in the composition of REO, the main components are the following: cineole, camphor, $\alpha$-pinene, camphene, and $\alpha$-terpineol $[38,39]$.

Sánchez-González et al. [33,40] established that the essential oil of Melaleuca alternifolia, also known as tea tree essential oil (TTO) is composed of terpene, mainly monoterpenes, sesquiterpenes, and tertiary alcohols [33,40-43]. The main components of TTO are terpineol, cineol, pinen, and terpinen and demonstrated antimicrobial activity $[40,44]$.

\subsection{Antifungal Activity of the Tested Essential Oils}

The antifungal activity of the essential oils against the three fungi strains examined was assessed by the percentage of the inhibition rate (IR\%) and minimum inhibitory concentration (MIC). In order to evaluate the quantity of essential oils needed to be used, a preliminary investigation was carried out with a volume of $10 \mu \mathrm{L}$ and $20 \mu \mathrm{L}$ of each of them. After this screening, the maximum concentration used was $60 \mu \mathrm{L}$, while the minimum volume used was $2.5 \mu \mathrm{L}$. The results presented in Figures 5-7 for the antifungal activity of the essential oils tested are the ones from the 7th day of analyses. From all tested oils, the most effective were the essential oils of clove, thyme, and tea tree. The efficacy of these essential oils can be attributed to the terpenes and phenylpropanoides present in their composition. The research studies demonstrated that phenolic compounds are responsible for the antifungal potential of these oils.

\subsubsection{Fusarium Graminearum G87}

Fusarium graminearum, being a plant pathogen, is a fungus commonly found in cereal grains (mostly wheat and barley). This pathogen has the potential to produce mycotoxines (deoxynivalenol and zearalonene) that have a negative impact on human and animal health [45]. The contamination of cereals by this toxigenic mold produces major economic impacts in agriculture.

The essential oils selected were tested against Fusarium graminearum, and the results are presented in Figure 5. 


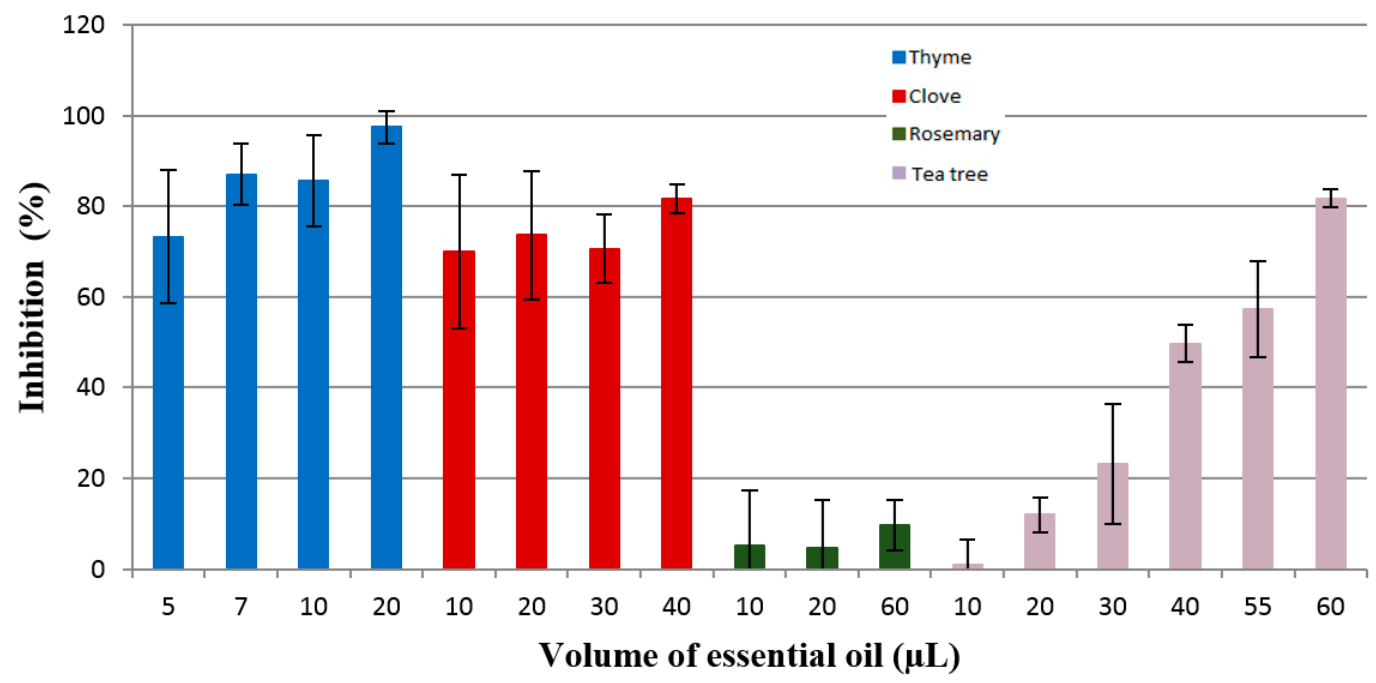

Figure 5. Inhibition of the Fusarium graminearum G87 growth by the thyme, clove, rosemary, and tea tree essential oils.

The fungal growth inhibition induced by essential oils, as determined by the disc diffusion assay, was dependent mostly on the volume (varying from $5 \mu \mathrm{L}$ to $60 \mu \mathrm{L}$ ) and nature of the essential oils. According to the results presented in Figure 5, it can be noticed that the essential oils tested had antifungal activity against Fusarium graminearum G87, but their efficacy is different. Thyme essential oil was the most effective, with an inhibition rate of over $80 \%$ at the lowest volume of essential oil used for the growth inhibition of this fungus, namely, $87.04 \%$ for $7 \mu \mathrm{L}$. Clove oil was also effective against the tested fungus, with an inhibition rate of $81.64 \%$ when using $40 \mu \mathrm{L}$. It is assumed that the high antifungal potential of clove essential oil is due to its active principle, eugenol (85.7\%). The results are in accordance with the study of Abbaszadeh et al. [46] regarding the effectiveness of eugenol against pathogenic fungi, which demonstrated that this phenylpropanoide had antifungal activity against all tested fungi. The antifungal activity was in direct ratio with the concentration of eugenol added to the media. In a study made by Marin et al. [47] who tested the efficacy of cinnamon, clove, oregano, palmarosa, and lemongrass oils against the mycotoxines produced by Fusarium graminearum, it was shown that clove essential oils was the most efficient against zearalenone and deoxynivalenol release.

Rosemary essential oil exhibits antifungal activity, but this was very low. For a volume of $60 \mu \mathrm{L}$ of this oil, the inhibition was below $10 \%$. Tea tree essential oil had an inhibition rate higher than $80 \%$ against $F$. graminearum $\mathrm{G} 87$ only for the highest volume used in this study $(60 \mu \mathrm{L})$.

\subsubsection{Penicillium Corylophilum CBMF1}

Penicillium corylophilum is a fungus that may cause the spoilage of bakery products; for this judgment, the essential oils selected were used to determine their antifungal activity against this mold.

Figure 6 shows the inhibition manifested by the tested essential oils against Penicillium corylophilum growth. 


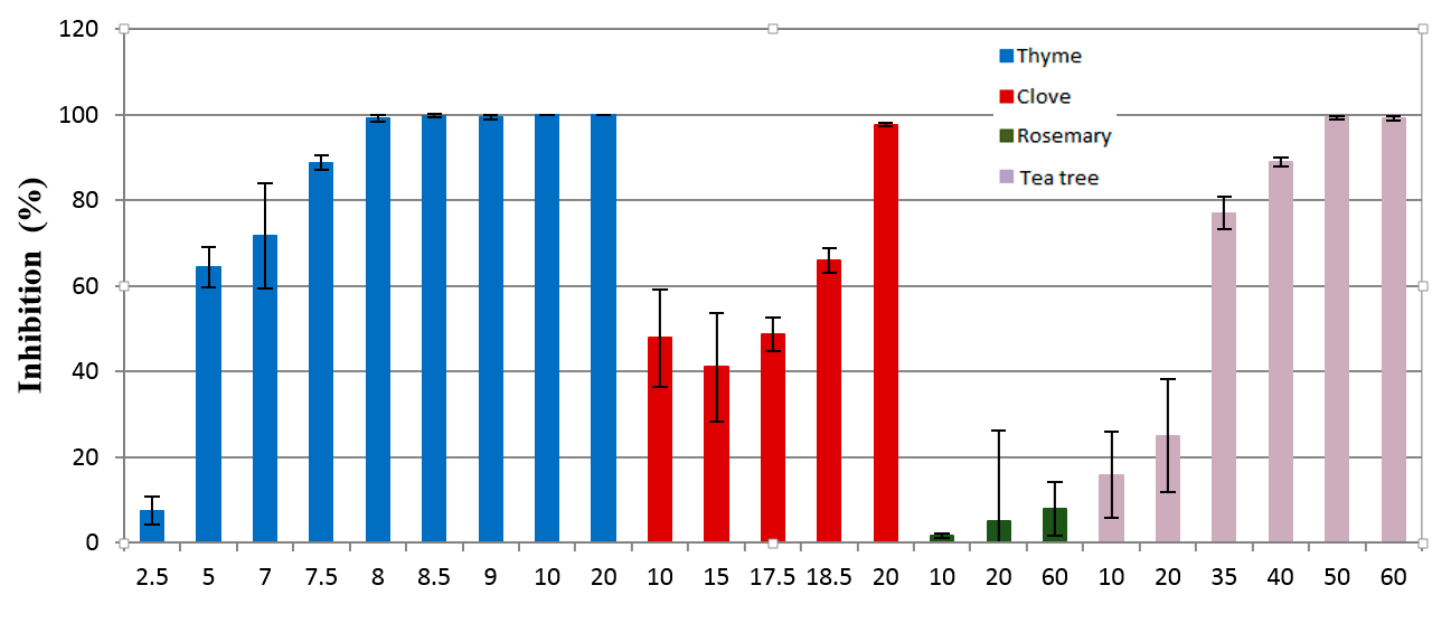

Volume of essential oil $(\mu \mathrm{L})$

Figure 6. Inhibition of the Penicillium corylophilum CBMF1 growth by the thyme, clove, rosemary, and tea tree essential oils.

The effectiveness of thyme oil as an antifungal agent can be noticed from the data presented in Figure 6. As can be seen, thyme essential oil is more active than clove essential oil, showing an inhibition rate of $100 \%$ at $10 \mu \mathrm{L}$, while clove oil was less effective $(I R=47.6 \%)$ at a volume of $10 \mu \mathrm{L}$. As well, tea tree essential oil has antifungal properties, but when a higher oil volume is used. It produced an inhibition of $89.04 \%$ for a quantity of $40 \mu \mathrm{L}$. It is considered that the antifungal activity of tea tree oil was significantly affected by the presence of high content of $\gamma$-terpinene (16.3\%), 4-terpineol $(38.7 \%)$, and $\alpha$-terpineol (4.6\%). Previous studies showed that tea tree oil has antifungal activity against Botrytis cinerea and Rhizopus stolonifer under in vitro conditions, inhibiting the spore germination and mycelial growth [43].

For the highest volume used in this study $(60 \mu \mathrm{L})$, rosemary oil did not inhibit the fungal growth of Penicillium corylophilum CBMF1, the IR being below $10 \%$.

\subsubsection{Aspergillus Brasiliensis ATCC 16404}

Aspergillus brasiliensis is a black mold that can spoil food products, especially fruits and vegetables [48].

The inhibition rate of the tested essential oils (thyme oil, clove oil, rosemary oil, tea tree oil) against Aspergillus brasiliensis ATCC 16404 is presented in Figure 7. The results presented evidenced that thyme oil was effective against $A$. brasiliensis ATCC 16404 at a volume of $5 \mu \mathrm{L}(I R=97.43 \%)$, while clove oil shows antifungal activity at a volume of $30 \mu \mathrm{L}(I R=82.64 \%)$. The strong antifungal activity of thyme oil is attributed to phenolic compounds carvacrol $(2.75 \%)$ and thymol $(43.1 \%)$, while the antimicrobial effectiveness of clove oil is associated with the activity of eugenol $(85.7 \%), \beta$-caryophyllene $(4.5 \%)$, and eugenol acetate (7.9\%). Similar studies were conducted by Abbaszadeh et al. [46], who tested the antifungal efficiency of thymol, carvacrol, eugenol, and menthol on growth inhibition of some important food-borne pathogens. The results showed that thymol and carvacrol inhibited the fungal growth of Cladosporium spp., Aspergillus spp., Fusarium oxysporum, Botrytis cinerea, Penicillium spp., Alternaria alternata, and Rhizopus oryzae, and the inhibition growth was dependent on the concentration used. 


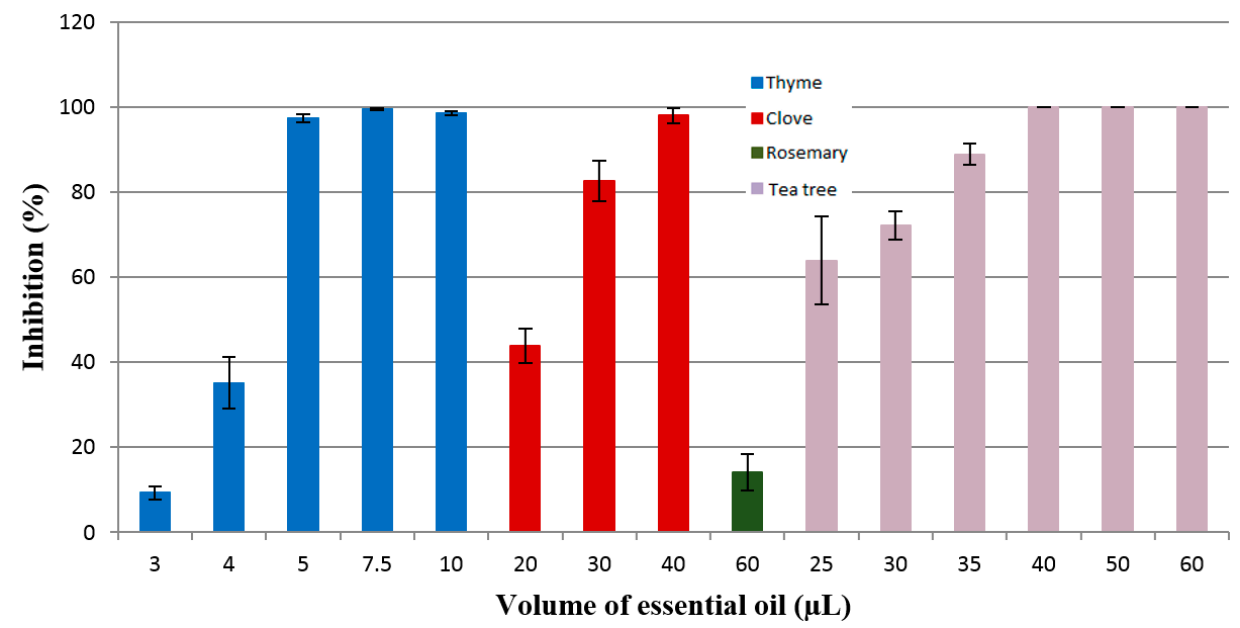

Figure 7. Inhibition of the Aspergillus brasiliensis ATCC 16404 growth by the thyme, clove, rosemary, and tea tree essential oils.

The essential oil of rosemary showed an inhibition rate of $14.22 \%$ for the volume of $60 \mu \mathrm{L}$. Jiang et al. [37] tested the antimicrobial activity of rosemary essential oil and its main components, $\alpha$-pinene and 1.8-cineole, against Gram-positive and Gram-negative bacteria and fungi (Candida albicans, Aspergillus niger). This study showed that the antimicrobial activity of rosemary essential oil was superior to its active compounds, and the essential oil is more active against all the bacteria used in this research compared to the tested fungi, concluding that the synergism between its compounds determine the antifungal activity.

Tea tree essential oil inhibited the growth of the tested fungus with an inhibition rate of $88.90 \%$ for a volume of $35 \mu \mathrm{L}$.

Comparing antifungal activity results of the studied essential oils, the following decreasing order of activity is evident: thyme oil $>$ clove oil $>$ tea tree oil $>>$ rosemary oil. Concerning the sensitivity to various fungi, the thyme oil and tea tree oil are very effective in the inhibition of the Aspergillus brasiliensis, as is clove oil in the inhibition of the Penicillium corylophilum. The rosemary oil is less effective as an antifungal agent but shows some activity against Aspergillus brasiliensis. However, other studies have evidenced that high-quality rosemary oil has antitumor, antifungal, and antiparasitic effects [49]. It has also analgesic, anticancer, anticatarrhal, anti-infection, anti-inflammatory, and expectorant properties and stimulates the circulatory system [50].

\subsection{Minimum Inhibitory Concentration}

The minimum inhibitory concentrations of the tested essential oils (EOs of thyme, clove, rosemary, and tea tree oils) are presented in Table 4.

Table 4. Minimum inhibitory concentration (MIC) of essential oils tested against Fusarium graminearum G87, Penicillium corylophilum CBMF1, and Aspergillus brasiliensis ATCC 16404.

\begin{tabular}{ccccc}
\hline Essential Oil Fungal Strain & $\begin{array}{c}\text { Thyme } \\
\text { (ppm) }\end{array}$ & $\begin{array}{c}\text { Clove } \\
\text { (ppm) }\end{array}$ & $\begin{array}{c}\text { Rosemary } \\
\text { (ppm) }\end{array}$ & $\begin{array}{c}\text { Tea Tree } \\
\text { (ppm) }\end{array}$ \\
\hline Penicillium corylophilum CBMF1 & 174.41 & 465.11 & NA & 930.23 \\
Fusarium graminearum G87 & 162.79 & 930.23 & NA & 1395.34 \\
Aspergillus brasiliensis ATCC 16404 & 116.27 & 697.67 & NA & 813.95 \\
\hline
\end{tabular}

NA—not applicable. 
The data presented in Table 4 shows that, from all the essential oils tested in this study, rosemary oil did not show desirable results against the selected fungi.

The results evidenced that the most effective essential oil from the tested oils was thyme essential oil, which displayed strong antifungal activity with MIC values between 116.27 and $174.41 \mathrm{ppm}$. MIC values of clove, rosemary, and tea tree essential oils were found within the range of 465.11-1395.34 ppm.

\subsection{Antibacterial Inhibition}

The antibacterial effect of EOs against the growth of S. aureus, E. coli, and L. monocytogenes was established by the agar disc diffusion method, and the results are presented in Figure 8 . On Mueller-Hinten (MH) agar plates, the inhibition zones of S. aureus are $64.7 \pm 1.2 \mathrm{~mm}$ for thyme oil, $27.8 \pm 3.4 \mathrm{~mm}$ for tea tree oil, $27.8 \pm 4.0 \mathrm{~mm}$ for clove oil, and $12.8 \pm 4.3 \mathrm{~mm}$ for rosemary oil. For E. coli, the inhibition zones are $35.5 \pm 4.6 \mathrm{~mm}$ for thyme oil, $27.0 \pm 3.4 \mathrm{~mm}$ for tea tree oil, $19.5 \pm 0.5 \mathrm{~mm}$ for clove oil, and $15.1 \pm 0.5 \mathrm{~mm}$ for rosemary oil. The diameters of the inhibition zones in the case of L. monocytogenes growth are of $69.5 \pm 6.4 \mathrm{~mm}$ for thyme oil, $22.0 \pm 2.8 \mathrm{~mm}$ for tea tree oil, and $28.5 \pm 2.1 \mathrm{~mm}$ for clove oil. There is no inhibition zone for rosemary.

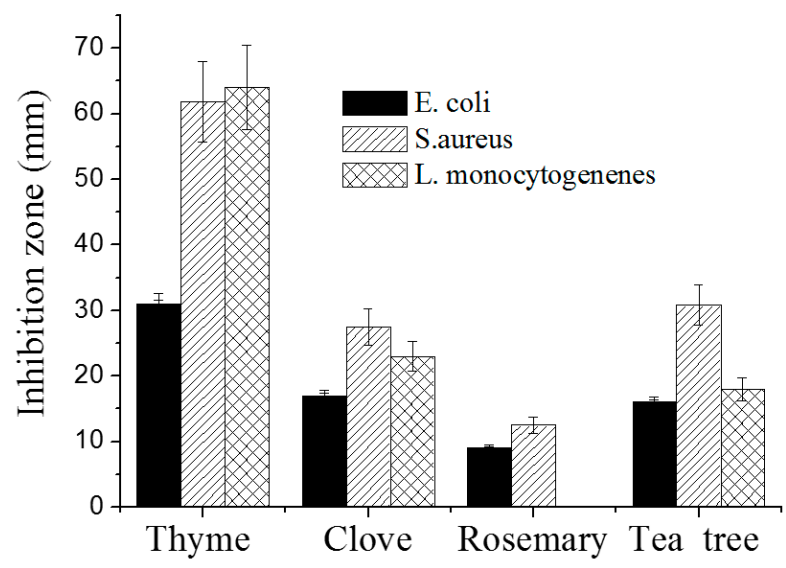

Figure 8. Antimicrobial activity of the four essential oils (EOs) $(10 \mu \mathrm{L}$ on each disc) against S. aureus, E. coli, and L. monocytogenes using the agar disc diffusion method on an Mueller-Hinten (MH) Plate.

Thyme oil had the highest inhibition zones for the three test strains, followed by tea tree oil, and then by clove oil. Rosemary oil was the least active.

Thyme essential oil is strongly antimicrobial, antifungal, antiviral, antiparasitic, mainly due to the high content of thymol [49]. This is in accordance with other studies that reported that thyme essential oil is efficient against Gram-positive and Gram-negative bacteria [29,30] and fungi [28,51,52].

Due to its antimicrobial, antifungal, antivermin, and antiviral activity [34,35], clove essential oil is used as a preservative but also exhibits other effects with positive impacts on consumer health, including antiseptic, antihelmintic, anti-inflammatory, antispastic, carminative, anti-neuralgic, antiulcer, anti-thrombotic, anticancerinogenic, and anticoagulant activities. Moreover, it acts as a local analgesic [36].

The inhibition zones observed after $24 \mathrm{~h}$ were stable and identical after 48 and $72 \mathrm{~h}$ of incubation. EOs are less effective in the vapor disc diffusion method compared to the disc diffusion method. Thyme and clove oils had volatile components that had inhibition zones even when the disc with EO had no contact with the bacteria. Thyme had the best effect for all test microorganisms, while clove only had an effect on S. aureus (Table 5). 
Table 5. Mean inhibition zone diameter $(\mathrm{mm})$ by the vapor disc diffusion method.

\begin{tabular}{cccc}
\hline \multirow{2}{*}{ Essential Oil } & \multicolumn{3}{c}{ Vapor Phase Method } \\
\cline { 2 - 4 } & S. aureus & E. coli & L. monocytogenes \\
\hline Thyme & $56.8 \pm 6.9$ & $28.3 \pm 1.3$ & $48.5 \pm 4.9$ \\
Clove & $14.2 \pm 2.6$ & $0 \pm 0$ & $0 \pm 0$ \\
Rosemary & $0 \pm 0$ & $0 \pm 0$ & $\mathrm{NA}$ \\
Tea tree & $0 \pm 0$ & $0 \pm 0$ & $0 \pm 0$ \\
\hline
\end{tabular}

The minimal inhibitory concentration of an antimicrobial agent is the lowest (i.e., minimal) concentration of the antimicrobial agent that inhibits a given bacterial isolate from multiplying and producing visible growth in the test system. This concentration was determined by incubating a known quantity of bacteria with specified dilutions of the antimicrobial agent. Using a similar broth dilution method, Zhang et al. [53] found that MIC was $1.0 \mathrm{mg} / \mathrm{mL}$ of cinnamon for both S. aureus and E. coli. Broth microdilution is the most widely used method in clinical laboratories, but agar diffusion is also used. Due to the oily content of EOs, using solvents is needed to obtain homogeneous dilutions. The results obtained using three solvents namely Tween-20, DMSO, and ethanol by the two test methods (agar MIC testing and the broth microdilution test) are shown in Table 6. There are some differences between the test results, but they all showed that thyme is the most effective EO, with a very low concentration needed to inhibit the growth of S. aureus and E. coli, followed by clove and tea tree oils. The thyme oil MIC values with the broth dilution method was approximately $0.39 \%-3.13 \%$ for S. aureus and $1.56 \%-3.13 \%$ for E. coli. Similarly, clove MIC value range were approximately $3.13 \%-6.26 \%$ for $S$. aureus and $6.25 \%$ for E. coli. A strong antimicrobial activity of thyme was also found by Mith et al. [54] when they tested different EOs and determined MIC against both food-borne pathogens and spoilage bacteria with a broth dilution method. The MIC value ranges of tea tree oil were approximately $0.80 \%-25.00 \%$ for S. aureus and $12.5 \%-25.00 \%$ for E. coli.

Table 6. The minimal inhibitory concentration (MIC) (\%) of essential oils in three different solvents $(v / v)$.

\begin{tabular}{cccccccc}
\hline \multirow{2}{*}{ EO } & \multirow{2}{*}{ Method } & \multicolumn{3}{c}{ MICs Value for S. aureus } & \multicolumn{2}{c}{ MICs Value for E. coli } \\
\cline { 3 - 7 } & & \multicolumn{2}{c}{ Concentration of Oil $(\boldsymbol{v} / \boldsymbol{v})$} & \multicolumn{2}{c}{ Concentration of Oil $(\boldsymbol{v} / \boldsymbol{v})$} \\
\hline \multirow{4}{*}{ Thyme } & $0.5 \%$ & $5 \%$ & $100 \%$ & $0.5 \%$ & $5 \%$ & $100 \%$ \\
& & Tween-20 & DMSO & Ethanol & Tween-20 & DMSO & Ethanol \\
\multirow{3}{*}{ Clove } & Agar & 1.56 & 12.50 & 1.56 & 3.13 & 6.25 & 1.56 \\
& Broth & 0.39 & 0.78 & 3.13 & 3.13 & 3.13 & 3.13 \\
\multirow{3}{*}{ Tea Tree } & Agar & 3.13 & 12.50 & 12.50 & 12.50 & 12.50 & 3.13 \\
& Broth & 6.25 & 3.13 & 3.13 & 6.25 & 6.25 & 6.25 \\
& Agar & 6.25 & 25.00 & 25.00 & 12.50 & 12.50 & 12.50 \\
& Broth & 0.80 & 25.00 & 25.00 & 12.50 & 25.00 & 25.00 \\
\hline
\end{tabular}

TTO has gained attention in the food industry for its antimicrobial [41,42] and antifungal activity [43], and it was successfully used in respiratory or genito-urinary tract infections [44].

\subsection{Antioxidant Activity Evaluation}

The results obtained by the ABTS method-Figure 9-are well correlated with those obtained by 2,2-diphenyl-1-picrylhydrazyl (DPPH)—Figure 10. 


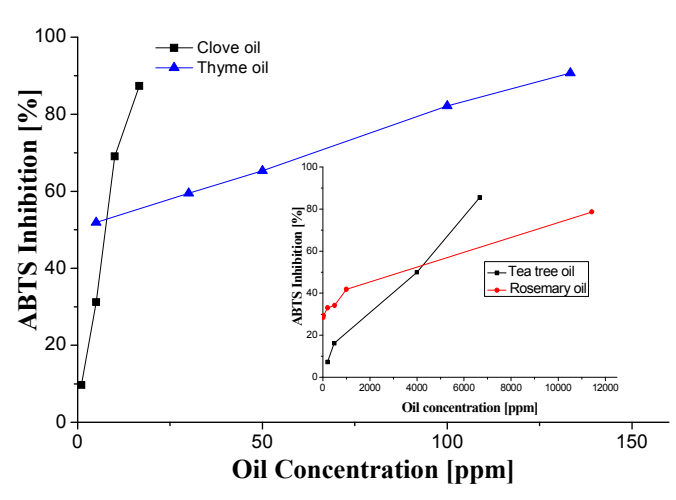

(a)

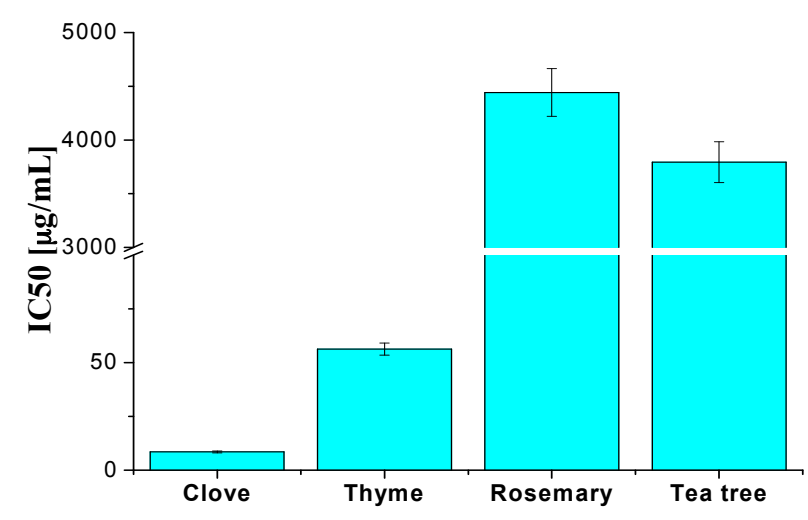

(b)

Figure 9. ABTS radical discoloration of studied essential oils (a) and the values of sample concentration required to scavenge $50 \%$ of the ABTS free radicals (IC50); (b) of selected essential oils.

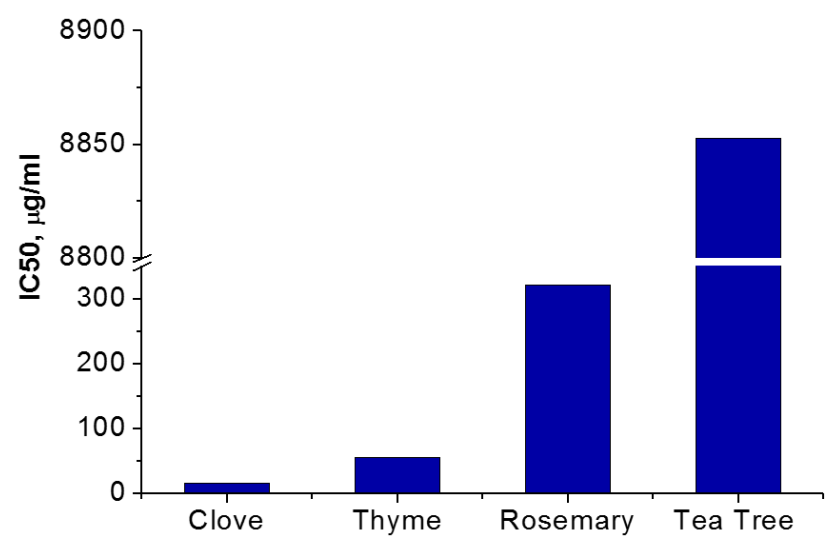

Figure 10. The values of the sample concentration required to scavenge $50 \%$ of the DPPH free radicals (IC50) of selected essential oils.

For the analyzed essential oils, IC50 is in the $\mu \mathrm{g} / \mathrm{mL}$ range assigned to a very good antioxidant activity [55]. From the selected essential oils, the clove oil is by far the most radical scavenging active, with an IC50 of $8 \mu \mathrm{g} / \mathrm{mL}$. The antioxidant activity was associated with the presence of phenolic compounds in the composition of essential oils, as determined by the Folin-Ciocâlteu method and the GC-FID technique and ORAC values. The antioxidant activity varies in the following order: clove oil > thyme oil > rosemary oil >> tea tree oil. Based on the radical scavenging tests, the clove oil is the most effective antioxidant is recommended for further such applications.

\subsection{Preliminary Results on the Use of Encapsulated Essential Oils into Chitosan Films as Food Packaging Material}

The stability of the chitosan/essential oil emulsions was sustained by dynamic light scattering (DLS) analysis, which showed a main particle population with low dimensions (Figure 11), with the distribution showing, in the low dimension range, a single peak and a polydispersity index (PDI)-approached value of 1.0 (Table 7). The chitosan/essential oil emulsions contain two kinds of particle populations: the first one is very small, where $d=5 \mathrm{~nm}$ for the chitosan solution and 11-70 (350) $\mathrm{nm}$ for the emulsion containing EOs, and the second contains larger particles of $850 \mathrm{~nm}$ for CS and 2500-8800 nm for CS/EOs emulsions. Oils are probably concentrated around CS particles because of aggregation. 


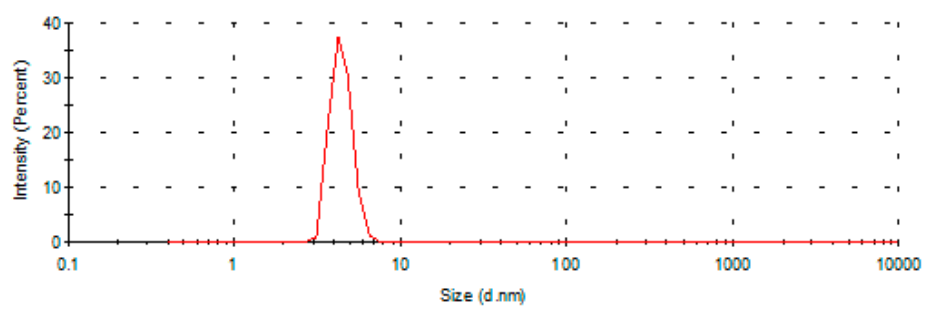

(a)

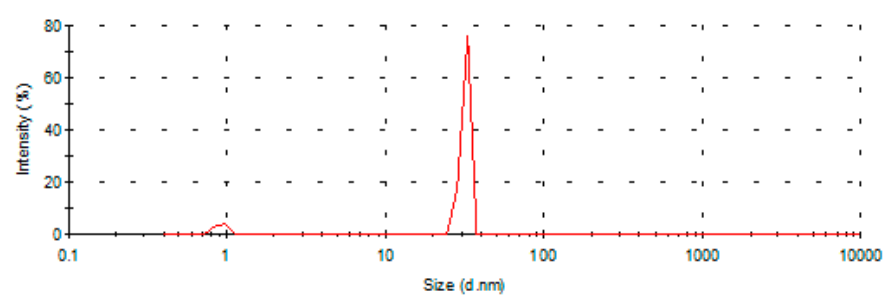

(b)

Figure 11. Particle size distribution of the chitosan (a) and chitosan/tea tree oil (b) emulsions in diluted acetic acid containing surfactant Tween 80 .

Table 7. DLS results for essential oil/chitosan emulsions used to obtain films for food packaging.

\begin{tabular}{cccc}
\hline Sample & Z First Peak, d (nm) & Z Average (nm) & PDI \\
\hline Chitosan & 5 & 850 & 0.997 \\
Thyme (Thymus Vulgaris L.) & 11.5 and 350 & 6190 & 0.735 \\
Cloves (Eugenia caryophyllus from dried & 10.5 & 8790 & 1.0 \\
floral buds of Syzygium aromaticum) & 60 & 2550 & 1.0 \\
Rosemary (Rosmarinus officinalis L.) & 15 and 70 & 6360 & 1.0 \\
Tea tree (Melaleuca alternifolia aetheroleum) &
\end{tabular}

Scanning electron microscopy examination reveals the morphology of the films obtained by the incorporation of essential oils into chitosan films-Figure 12. The films are relatively homogeneous, and dispersion of the essential oil in the film obtained by solvent casting is homogeneous, as is evident from the SEM images taken at high magnification $(2000 \times)$.

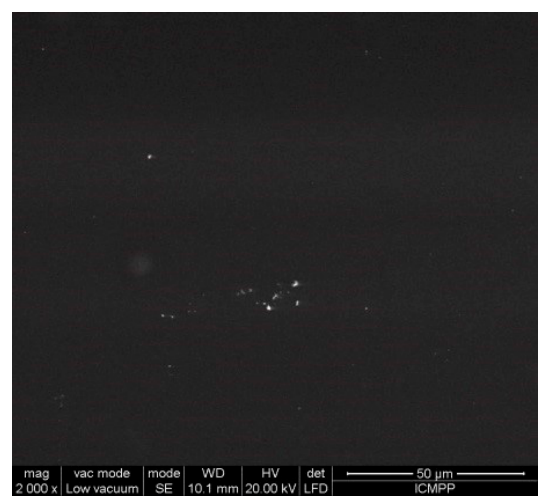

(a)

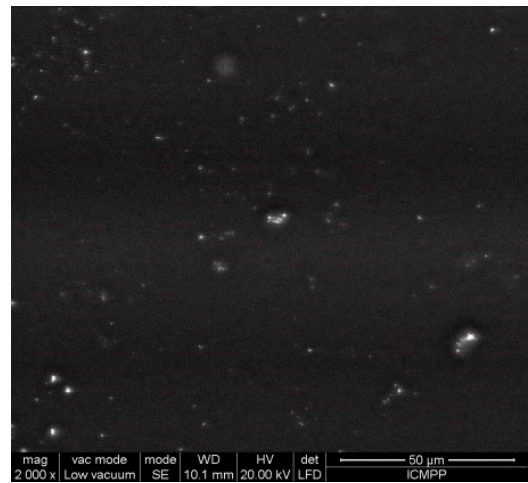

(b)

Figure 12. SEM images of (a) CS and (b) CS/rosemary or clove oil/T80 films at a $2000 \times$ magnification. 
It can be observed that the surfaces are very smooth, and, by essential oil incorporation, very small particles are evidenced at high magnification. The good homogeneity of the films and the encapsulation of the oils is assured by the presence of a nonionic surfactant and emulsifier T80.

The encapsulation of active (antimicrobial and antioxidant) essential oils into the chitosan matrix leads to a significant decrease in the total number of germs for beef meat packed in such films-from $2400-1020 \mathrm{CFU} / \mathrm{cm}^{2}$ for films containing only CS to $700 \mathrm{CFU} / \mathrm{cm}^{2}$ for films containing both CS and clove oil. These films proved to have a good antimicrobial activity for delaying the spoilage of beef meat, with both antimicrobial agents acting synergistically [56]. This research will be the topic of the subsequent paper.

\section{Experimental Section}

\subsection{Materials}

\section{Essential Oils}

Four commercial essential oils used in this study were purchased from the Fares company (Orăştie, Romania): thyme (Thymus Vulgaris L.), clove (Eugenia caryophyllus_from dried floral buds of Syzygium aromaticum), rosemary (Rosmarinus officinalis L.), and tea tree (Melaleuca alternifolia aetheroleum) obtained using a distillation apparatus (according to European Pharmacopoeia 7th edition, method 8.2.12).

The Folin-Ciocâlteu phenol reagent 2N was purchased from Sigma-Aldrich (Buchs, Switzerland), and sodium carbonate decahydrate $\left(\mathrm{Na}_{2} \mathrm{CO}_{3} \cdot 10 \mathrm{H}_{2} \mathrm{O}, \mathrm{M}=286.14\right)$ was from Chimopar S.A., Bucuresti, Romania. Methanol and gallic acid $(97 \%, M=170.12)$ were purchased from Sigma-Aldrich (Buchs, Switzerland).

For the determination of the antioxidant activity 2,2-diphenyl-1-picrylhydrazyl (DPPH, Sigma-Aldrich, Darmstadt, Germany), 2,2'-azino-bis(3-ethylbenzothiazoline-6-sulfonic acid) diammonium salt (ABTS, purity $\geq 98 \%$ by HPLC, Sigma-Aldrich, Darmsadt, Germany) and potassium persulfate (KPS, ACS reagent, purity $\geq 99.0 \%$, Fluka, Buchs, Switzerland) were used. High purity solvents such as Tween-20 from Sigma-Aldrich (Buchs, Switzerland) containing lauric acid, $\geq 40 \%$ (balance primarily myristic, palmoyic, and stearic acids; dimethyl sulfoxide (DSMO, Sigma-Aldrich, Buchs, Switzerland), or ethanol (Sigma-Aldrich, Buchs, Switzerland) were used in the antibacterial activity test.

Chitosan (CS) from crab shells, with a dynamic viscosity of $>400 \mathrm{mPa} \cdot \mathrm{s}$ in $1 \%$ acetic acid $\left(20^{\circ} \mathrm{C}\right)$ where $M W=310,000-375,000 \mathrm{~g} / \mathrm{mol}$, was purchased from Sigma-Aldrich (Buchs, Switzerland).

Polysorbate 80 or Tween ${ }^{\circledR} 80$ (T80) is a viscous, water-soluble viscous yellow liquid, a nonionic surfactant and emulsifier often used in foods and cosmetics. It was offered by Sigma-Aldrich (Buchs, Switzerland) for research purposes.

\subsection{Microorganisms}

\subsubsection{Fungi}

Three food-related fungi were used as target microorganisms in this study: Aspergillus brasilliensis ATCC 16404, Penicillium corylophilum CBMF1, and Fusarium graminearum G87, and they were provided from the collection of Faculty of Biotechnology of University of Agronomic Sciences and Veterinary Medicine Bucharest (Bucharest, Romania).

\subsubsection{Bacteria}

The three tested bacterial strains were obtained from the Culture Collection at the University of Gothenburg: Staphylococcus aureus CCUG 1828, Escherichia coli CCUG 10979, and Listeria monocytogenes CCUG 15527. A test culture was prepared by growth on MH agar overnight, and colonies were diluted to a $0.5 \mathrm{McF}$ arland in MH broth. 


\subsection{Methods of Investigation}

3.3.1. Determination of Total Phenolic Content in Vegetable Oils by the Folin-Ciocâlteu Reagent Method

The amount of total phenols was determined by the Folin-Ciocâlteu reagent method as described by Scalbert et al. [18]. A $10 \mu \mathrm{L}$ volume of essential oil was dissolved in $10 \mathrm{~mL}$ of methanol, and $0.1 \mathrm{~mL}$ of methanol solution was then transferred into a volumetric flask and diluted with $0.4 \mathrm{~mL}$ of double distilled water and used for analysis. A Folin-Ciocâlteu reagent solution 1:10 $v / v$ in double distilled water $(1 \mathrm{~mL})$ was added to the diluted methanol/oil mixture $(0.5 \mathrm{~mL})$, which was then mixed thoroughly and leaved for 10 minutes at room temperature. A $2 \mathrm{~mL}$ solution based on $15 \%$ sodium carbonate $\left(\mathrm{Na}_{2} \mathrm{CO}_{3} \cdot 10 \mathrm{H}_{2} \mathrm{O}\right)$ was added; after $1 \mathrm{~h}$ of incubation at room temperature, the absorbance was measured at $740 \mathrm{~nm}$ with a UV-Vis 60 Cary spectrophotometer against a blank sample that was concomitantly prepared. The blank sample contained $0.1 \mathrm{~mL}$ of methanol without oil, $0.4 \mathrm{~mL}$ of water, $1 \mathrm{~mL}$ of a Folin-Ciocâlteu reagent solution, and $2 \mathrm{~mL}$ of a $\mathrm{Na}_{2} \mathrm{CO}_{3} \cdot 10 \mathrm{H}_{2} \mathrm{O}$ solution. Gallic acid was used as the standard for the calibration curve, which was drawn using solutions of the gallic acid in methanol of different concentrations ranging between 0.01 and $1 \mathrm{mg} / \mathrm{mL}$. Based on the measured absorbance at $740 \mathrm{~nm}$, the concentration of phenolics was read $(\mathrm{mg} / \mathrm{mL})$ from the calibration line, and the total phenolics values were then expressed as mg.GAE/g.DW. Each determination was made in triplicate, and average values were reported.

3.3.2. Gas Chromatography-Mass Spectrometry Detector and Flame-Ionized Detector Analysis (GC-MSD/FID)

The essential oils were characterized by gas chromatography coupled with mass spectrometry detector (GC-MSD) for qualitative analysis and, with a flame ionized detector (GC-FID) (Agilent, Santa Clara, CA, USA), quantitative analysis.

The GC analysis was performed on a 6890 Agilent Technologies chromatograph using the following parameters: a Teknokroma TR-520232 (95\% dimethyl- and 5\% diphenyl-polysiloxane, crosslinked; $30 \mathrm{~m} \times 250 \mu \mathrm{m} \times 0.25 \mu \mathrm{m}$ ) capillary column, a $1 \mathrm{~mL} / \mathrm{min}$ helium flow, an inlet at $175^{\circ} \mathrm{C}$, a 100:1 split ratio, and a temperature program starting at $60^{\circ} \mathrm{C}$, with a heating rate of $7{ }^{\circ} \mathrm{C} / \mathrm{min}$ up to $200{ }^{\circ} \mathrm{C}$ and then $15^{\circ} \mathrm{C} / \mathrm{min}$ up to $300^{\circ} \mathrm{C}$, followed by isothermal heating at $300{ }^{\circ} \mathrm{C}$ for $3.33 \mathrm{~min}$.

The MS detection was performed on a 5975 Inert XL Agilent Technologies detector (Agilent, Santa Clara, CA, USA), at $70 \mathrm{eV}$. Identification of chromatographic peaks was made by reference to Institute of Standards and Technology (NIST) database, with a quality of recognition above $90 \%$.

\subsection{Fungi Spore Suspension Preparation}

To evaluate the antifungal activity of the tested essential oils, the selected fungi were grown on a Potato Dextrose Agar (PDA, Scharlau Microbiologi, Barcelona, Spain) medium in $90 \mathrm{~mm}$ Petri dishes for 7-9 days and stored at $25^{\circ} \mathrm{C}$. Fungal spore suspension was obtained in aseptic conditions in a laminar flow cabinet after ultraviolet sterilization for $20 \mathrm{~min}$. Fungal spore suspensions were collected from the surface of fungal colonies by gentle scraping with a sterile inoculation loop and suspended in $10 \mathrm{~mL}$ of sterile water. Spore population was counted using a hemocytometer (Thoma camera, 0, $100 \mathrm{~mm}$ depth, from Hirschmann Techcolor, Eberstadt, Germany). The concentration of spore suspensions was $10^{6}$ spores $/ \mathrm{mL}$.

\subsection{Antifungal Assay}

The antifungal activity of the tested oils was determined with the disc diffusion method. Potato dextrose agar medium was poured into $90 \mathrm{~mm}$ Petri dishes, and, after its solidifying, in each Petri dish, $100 \mu \mathrm{L}$ of spore suspensions (containing $10^{6}$ spores $/ \mathrm{mL}$ ) were spread onto the surface of the media. The dishes were left to facilitate the incorporation of fungi in the PDA medium for $30 \mathrm{~min}$. Subsequently, filter paper discs ( $6 \mathrm{~mm} \varnothing$; Whatman) were placed on the surface of the Petri dishes and 
impregnated with different amounts (volume from 2.5 to $60 \mu \mathrm{L}$ ) of essential oil. All determinations were performed in five replicates. Control plates (without essential oils) were inoculated using the same procedure. Each sample was evaluated by three analysts, and three averages of the five replicates were obtained. The final average is the arithmetic average of the three other averages. Samples were evaluated through estimation of the degree to which the Petri dish surface was covered by fungal mycelium and through an inhibition rate (IR) calculation.

The inhibition rate was calculated as follows:

$$
\operatorname{IR}(\%)=\frac{C-S}{C} \times 100
$$

where $C$ is the rate of the fungal mycelium growth of the control, and $S$ is the rate of the fungal mycelium growth of the samples.

The dishes were sealed with parafilm tape to prevent the volatilization of essential oils and incubated for 7 days at $25^{\circ} \mathrm{C}$. The efficacy of the treatment was evaluated after 7 days by the inhibition rate $I R(\%)$.

\subsection{Determination of the Minimum Inhibitory Concentration (MIC) of Fungi}

Essential oils were screened to determine their minimum inhibitory concentration against the food spoilage microorganisms selected. The same procedure as the one described for the antifungal assay was used to determine the minimum inhibitory concentration (MIC). The definition of the MIC differs between various publications [57-59], so it was decided that the MIC would be defined as the lowest volume of essential oil that inhibited the growth of the tested fungi with an inhibition rate higher than $80 \%$. The MIC is expressed in different units including $\mathrm{mg} / \mathrm{mL}[60], \mu \mathrm{g} / \mathrm{mL}[61,62]$, $\mu \mathrm{L} / \mathrm{L}[63,64], \mu \mathrm{L} / \mathrm{mL}[65]$, and ppm [62,66]. In this study, the MIC of fungi was expressed as ppm.

\subsection{The Agar Disc Diffusion Method}

The protocol of the Clinical and Laboratory Standards Institute (CLSI) $[67,68]$ was followed with some modifications. The bacterial suspensions were diluted to a McFarland standard of 0.5 ( $0.5 \mathrm{McF}$ arland standard is prepared by mixing $0.05 \mathrm{~mL}$ of $1.175 \%$ barium chloride dihydrate $\left(\mathrm{BaCl}_{2} \cdot 2 \mathrm{H}_{2} \mathrm{O}\right)$, with $9.95 \mathrm{~mL}$ of $1 \%$ sulfuric acid $\left(\mathrm{H}_{2} \mathrm{SO}_{4}\right)$, and adjusted to about $10^{4}-10^{5}$ bacteria $/ \mathrm{mL}$ before use. A $0.1 \mathrm{~mL}$ portion from this bacterial dilution was spread on Mueller-Hinten (MH) agar (MHA, Sigma-Aldrich, Darmstadt, Germany). Subsequently, sterile paper discs (Macherey-Nagel, Düren, Germany, LOT: 141112) $6 \mathrm{~mm}$ in diameter were placed within 15 min onto the inoculated agar surface containing $10 \mu \mathrm{L}$ of the essential oil or $10 \mu \mathrm{L}$ of sterile water as control. Petri dishes were incubated at $37^{\circ} \mathrm{C}$ for $24 \pm 1 \mathrm{~h}$. After incubation, the inhibition zones were measured as the complete inhibition in $\mathrm{mm}$, as a diameter including the disc. The inhibition zones were measured in triplicate with a vernier caliper. The distance from the colonies closest to the disc to the center of the disc was doubled to obtain a diameter.

\subsection{The Vapor Disc Diffusion Method}

MH-agar plate surfaces inoculated with E. coli and S. aureus and Tryptone Soya Agar (TSA, CM 0131, Oxoid Ltd., Thermo Fisher Scientific, Basingstoke, Hampshire, UK) with L. monocytogenes were prepared as described in Section 3.7. A volume of $10 \mu \mathrm{L}$ of each pure EO was added to sterile filter discs with a diameter of $6 \mathrm{~mm}$, and sterile water was used as control. The discs were placed on the inside center of a Petri dish lid in a sterile working hood. A control was also prepared by adding $10 \mu \mathrm{L}$ of sterile water to the filter discs.

The inoculated agar plate was then placed to fit the lid but with the agar upwards. This created a closed Petri dish with a distance of about $1 \mathrm{~cm}$ between the disc and the bacteria inoculated agar surface in accordance with Goni et al. [69]. The Petri dishes were sealed with adhesive tape to prevent volatile components of the essential oils to escape. 


\subsection{Determination of the Minimum Inhibitory Concentration (MIC) of Bacteria}

\subsubsection{Agar MIC Testing}

The preparation of agar, broth, and bacteria were carried out as described in Section 3.7. MICs was determined for thyme, clove, and tea tree against $S$. aureus and E. coli according to the method used by Zhang and Mith $[53,54]$ with some minor modifications. The original solution of each EO was dissolved in Tween-20 (0.5\%), dimethyl sulfoxide (DSMO, $5 \%)$, or ethanol $(100 \%)$ in a 1:1 ratio to make serial 2-fold dilutions, yielding solutions with a gradient from $100 \%$ oil to $0.2 \%$ oil $(v / v)$. A volume of $10 \mu \mathrm{L}$ of each oil dilution was added to the $6 \mathrm{~mm}$ paper disc and then placed on $\mathrm{MH}$ agar plates with a $100 \mu \mathrm{L}$ bacterial concentration containing a $10^{4}-10^{5} \mathrm{CFU} / \mathrm{mL}$ suspension of each tested bacterium. DSMO without bacteria was used as a control.

\subsubsection{Broth Microdilution MIC Testing}

Similar dilutions in either Tween-20 (0.5\%), dimethyl sulfoxide (DSMO, 5\%), or ethanol (100\%) were transferred to sterile microtiter plates (honeycomb plates with 100 wells). Three parallel dilution series were used with $100 \mu \mathrm{L}$ in each well. The microtiter plates were mounted in a Bioscreen C (Oy Growth Curves Ab Ltd., Helsinki, Finland), an automated growth curve analysis system, programmed to measure absorbance at $600 \mathrm{~nm}($ abs $600 \mathrm{~nm})$ at regular time intervals at $37 \pm 0.1^{\circ} \mathrm{C}$. Prior to each measurement, the plates were shaken for $10 \mathrm{~s}$ (default setting). Growth curves of both strains were recorded. Time-to-detection (TTD) were defined as $A B S_{600 \mathrm{~nm}}=0.2$. Lack of absorbance above 0.2 were defined as growth inhibition.

\subsection{Antioxidant Activity Evaluation}

The inhibition concentration of four essential oils (thyme, clove, rosemary, and tea tree) and the stability of natural antioxidant at different concentrations were evaluated using 2,2'-azino-bis 3-ethylbenzthiazoline-6-sulfonic acid (ABTS) and 2,2-diphenyl-1-picrylhydrazyl (DPPH) radical methods.

3.10.1. ABTS ${ }^{\bullet+}\left(2,2^{\prime}\right.$-Azino-bis 3-ethylbenzthiazoline-6-sulfonic Acid) Radical Cation Scavenging Assay

The $\mathrm{ABTS}^{\bullet+}$ scavenging test is used to determine the antioxidant activity of both hydrophilic and hydrophobic compounds. ABTS ${ }^{\bullet+}$ is generated by mixing $2.5 \mathrm{~mL}$ of $7 \mathrm{mM}$ ABTS with $2.5 \mathrm{~mL}$ of $14.7 \mathrm{mM}$ potassium persulfate (KPS) water solutions and stored in the dark at room temperature for $16 \mathrm{~h}$. The reaction between $\mathrm{ABTS}^{\bullet+}$ and potassium persulfate directly generates the blue green $\mathrm{ABTS}^{\bullet+}$ chromophore, which can be reduced by an antioxidant, thereby resulting in a loss of absorbance at $750 \mathrm{~nm}$.

The antioxidant capacity is expressed as percentage inhibition, calculated using the following formula [70]:

$$
\operatorname{Inhibition}(\%)=\left[\frac{A_{\text {control }}-A_{\text {sample }}}{A_{\text {control }}} \times 100\right]
$$

where $A_{\text {control }}$ is the absorbance of the ABTS radical in methanol, and $A_{\text {sample }}$ is the absorbance of an ABTS radical solution mixed with the sample. All determinations were performed in triplicate.

\subsubsection{DPPH Radical Scavenging Assay}

The DPPH radical scavenging assay for essential oils was measured using the 2,2-diphenyl-1-picrylhydrazyl (DPPH) radical. The DPPH is a stable free radical with a violet color that, under the action of proton-donating compounds, is reduced to a light yellow color, and this change can be monitored at $517 \mathrm{~nm}$ [71]. Concentrations of the methanolic solution between 0.156 and $20 \mathrm{mg} / \mathrm{mL}$ were tested. 
The radical scavenging activity was calculated according to the following equation:

$$
\% R S A=100 \times\left(\frac{A_{\text {control }}-A_{\text {sample }}}{A_{\text {control }}}\right)
$$

where $A_{\text {sample }}$ represents the absorbance of the sample solution in the presence of DPPH, and $A_{\text {control }}$ is the absorbance of the standard DPPH solution. For more details, see ref. [72].

\subsection{The Encapsulation of Essential Oils into the Chitosan Matrix by the Emulsion/Solvent Casting Method}

The film forming solutions were prepared using highly viscous chitosan from crab shells where $M W=310,000-375,000 \mathrm{~g} / \mathrm{mol}$, with a dynamic viscosity of $>400 \mathrm{mPa} \cdot \mathrm{s}$ in $1 \%$ acetic acid $\left(20^{\circ} \mathrm{C}\right)$. The chitosan film-forming solution was prepared by dissolving $2 \mathrm{~g}$ of chitosan per $100 \mathrm{~mL}$ of a 5\% acetic acid aqueous solution. Food grade essential oils (clove, thyme, rosemary, and tea tree oils) were incorporated in a proportion of $0.75 \mathrm{~mL} / \mathrm{g}$ chitosan, and Tween 80 (Sigma-Aldrich, Darmstadt, Germany) ( $0.125 \mathrm{~g} / \mathrm{g}$ chitosan) was added as an emulsifying agent. The essential oil-added film-forming solution was homogenized with an ultrasonic processor UP50H (Hielscher-Ultrasound Technology, Teltow, Germany) using a power of $50 \mathrm{~W}$ at $30 \mathrm{kHz}$ ). The films were obtained by casting $50 \mathrm{~mL}$ in glass Petri dishes $\left(153 \mathrm{~cm}^{2}\right)$ and drying first at $25^{\circ} \mathrm{C}$ in a forced-air oven for $24 \mathrm{~h}$ and then at $40{ }^{\circ} \mathrm{C}$ in a vacuum oven to yield a uniform thickness in all cases. Prior to analyses, the films were conditioned in desiccators for 2 days at $22{ }^{\circ} \mathrm{C}$ over a saturated solution of $\mathrm{NaBr}(58 \%$ relative humidity) [56].

\subsection{The Dynamic Light Scattering (DLS) Analysis}

The DLS analysis of the oils-in-chitosan emulsions was carried out using a Zetasizer NS (Malvern Instruments Ltd., Malvern, UK), according with standard ISO 13321 (1996). This analysis only gives a mean particle size (z-average) and an estimate of the width of the distribution (polydispersity index (PDI)). It is very sensitive to the presence of aggregates due to the inherent intensity weighting. The oil/chitosan ratio was kept at $0.75 \mathrm{~mL} / 1 \mathrm{~g}$ chitosan. For DLS, the concentration of the initial solution was $1.5 \mathrm{wt} \%$ chitosan and the corresponding concentration of the oils. The chitosan/essential oil emulsions of $1.5 \mathrm{wt} \%$ were diluted three times prior to analysis with the $5 \mathrm{wt} \%$ acetic acid aqueous solution.

\subsection{Scanning Electron Microscopy (SEM)}

SEM examination was carried out using QUANTA 200 scanning electronic microscope (FEI Company, Hillsboro, OR, USA), with an integrated EDX system, GENESIS XM 2i EDAX (FEI Company, Hillsboro, OR, USA) with a SUTW detector and without any further treatments at different magnifications given on the image micrographs.

\subsection{Statistical Analysis}

Each analysis was performed in five replicates. Data were analyzed statistically with the one-way analysis of variance ANOVA test using the SPSS statistics. Significant differences between tested samples and the control were defined at $p<0.05$.

\section{Conclusions}

Based on GC-MSD/FID analysis, it has been established that the commercially available thyme, rosemary, clove, and tea tree essential oils correspond to AFNOR/ISO standards.

The results of this study demonstrate the potential of thyme oil, clove oil, and tea tree oil for use as antifungal agents against tested fungi strains (Fusarium graminearum G87, Penicillium corylophilum CBMF1, and Aspergillus brasiliensis ATCC 16404) and three potential pathogenic food bacteria: Staphylococcus aureus, Escherichia coli, and Listeria monocytogenes. The overall results of the MIC values 
show that thyme oil is the most effective with a very low concentration used against both on the three fungi and bacteria, followed by clove and tea tree oils, while the rosemary oil is less active or inactive.

Concerning the antioxidant activity, the IC50 of the analyzed essential oils is in the $\mu \mathrm{g} / \mathrm{mL}$ range that is assigned to a very good antioxidant activity which varies in the following order: clove oil $>$ thyme oil > rosemary oil > tee tree oil, and the clove oil exhibits the highest radical scavenging activity.

Promising results were obtained by their incorporation into chitosan emulsions and films, with potential applications in food packaging that will be detailed in a future paper. Taking into account their biological activity in addition, it is expected that their use can also benefit consumers' health.

On the basis of the obtained results, it can be concluded that these essential oils can be suitable alternatives to chemical additives, satisfying the consumer demand for naturally preserved food products and ensuring their safety at the same time.

Acknowledgments: The research leading to these results was funded by the Romanian EEA Research Programme operated by MEN under the EEA Financial Mechanism 2009-2014, project contract No. 1SEE/2014. We also thank the Norwegian Research council for its financial support, and Bioing. A. Diaconu for the DLS measurements.

Author Contributions: C.V., M.S., A.C.M., M.A.B., and E.S. designed research; E.S., M.A.B., J.T.R., E.E.T., W.K., D.P., C.P.C., and A.I. performed research; C.V., M.S., A.C.M., M.A.B., E.S., and D.P. analyzed the data; C.V., M.S., and A.C.M. wrote the paper. All authors read and approved the final manuscript.

Conflicts of Interest: The authors declare no conflict of interest.

\section{References}

1. Pasha, I.; Saeed, F.; Sultan, M.T.; Khan, M.R.; Rohi, M. Recent Developments in Minimal Processing: A Tool to Retain Nutritional Quality of Food. Crit. Rev. Food Sci. Nutr. 2014, 54, 340-351. [CrossRef] [PubMed]

2. NOTIZIE DALLA WHO. Food safety and foodborne illness. Biochim. Clin. 2002, 26, 39.

3. WHO; WIPO; WTO. Antimicrobial Resistance: How to Foster Innovation, Access and Appropriate Use of Antibiotics? In Proceedings of the a Joint Technical Symposium by WHO, WIPO and WTO, New Conference Hall, WIPO Headquarters, Geneva, Switzerland, 25 October 2016.

4. Burt, S. Essential oils: Their antibacterial properties and potential applications in foods-A review. Int. J. Food Microbiol. 2004, 94, 223-253. [CrossRef] [PubMed]

5. Helander, I.M.; Alakomi, H.-L.; Latva-Kala, K.; Mattila-Sandholm, T.; Pol, I.; Smid, E.J.; Gorris, L.G.M.; von Wright, A. Characterization of the action of selected essential oil components on Gram-Negative Bacteria. J. Agric. Food Chem. 1998, 46, 3590-3595. [CrossRef]

6. Bozin, B.; Mimica-Dukic, N.; Simin, N.; Anackov, G. Characterization of the volatile composition of essential oils of some lamiaceae spices and the antimicrobial and antioxidant activities of the entire oils. J. Agric. Food Chem. 2006, 54, 1822-1828. [CrossRef] [PubMed]

7. Potzernheim, M.C.L.; Bizzo, H.R.; Silva, J.P.; Vieira, R.F. Chemical characterization of essential oil constituents of four populations of Piper aduncum L. from Distrito Federal, Brazil. Biochem. Syst. Ecol. 2012, 42, 25-31. [CrossRef]

8. Colecio-Juárez, M.C.; Rubio-Núñez, R.E.; Botello-Álvarez, J.E.; Martínez-González, G.M.; Navarrete-Bolaños, J.L.; Jiménez-Islas, H. Characterization of Volatile Compounds in the Essential Oil of Sweet Lime (Citrus limetta Risso). Chilean J. Agric. Res. 2012, 72, 275-280. [CrossRef]

9. Santiago, J.A.; Cardoso, M.G.; Figueiredo, A.C.S.; Moraes, J.C.; Assis, F.A.; Teixeira, M.L.; Santiago, W.D.; Sales, T.A.; Camargo, K.C.; Nelson, D.L. Chemical Characterization and Application of the Essential Oils from Chenopodium ambrosioides and Philodendron bipinnatifidum in the Control of Diabrotica speciosa (Coleoptera: Chrysomelidae). Am. J. Plant Sci. 2014, 5, 3994-4002. [CrossRef]

10. Dhole, V.R.; Sitharaman, B. Characterization and Identification of Essential Oil Components by GC-MS. Available online: https://tools.thermofisher.com/content/sfs/posters/Pittcon12_2160-3_VRDhole_ EssentialOils(1).pdf (accessed on 4 January 2017).

11. Wany, A.; Kumar, A.; Nallapeta, S.; Jha, S.; Nigam, V.K.; Pandey, D.M. Extraction and characterization of essentail oil components based on geraniol and citronellol from Java Citronella (Cymbopogon winterianus Jowitt). Plant Growth Regul. 2014, 73, 133-145. [CrossRef] 
12. Chukwuka, K.S.; Ojo, O.M. Extraction and Characterization of Essential Oils from Tithonia diversifolia (Hemsl.) A. Gray. Am. J. Essent. Oils Nat. Prod. 2014, 1, 1-5.

13. Labra, M.; Miele, M.; Ledda, B.; Grassi, F.; Mazzei, M.; Sala, F. Morphological characterization, essential oil composition and DNA genotyping of Ocimum basilicum L. cultivars. Plant Sci. 2004, 167, 725-731. [CrossRef]

14. Jalali-Heravi, M.; Zekavat, B.; Sereshti, H. Characterization of essential oil components of Iranian geranium oil using gas chromatography-mass spectrometry combined with chemometric resolution techniques. J. Chromatogr. A 2006, 1114, 154-163. [CrossRef] [PubMed]

15. Moldovan, I.; Oprean, R. Comparative Study of Essential Oil from Two Species of Mint Grown in Orăştie. Farmacia 2014, 62, 169-182.

16. Prabuseenivasan, S.; Jayakumar, M.; Ignacimuthu, S. In vitro antibacterial activity of some plant essential oils. BMC Complement. Altern. Med. 2006, 6, 39. [CrossRef] [PubMed]

17. World Health Organization. WHO Monographs on Selected Medicinal Plants; WHO: Geneva, Switzerland, 2002; Volume 2.

18. Krisch, J.; Tserennadmid, R.; Vágvölgyi, C. Essential Oils against Yeasts and Moulds Causing Food Spoilage in SCIENCE against Microbial Pathogens: Communicating Current Research and Technological Advances; Méndez-Vilas, A., Ed.; OFORMATEX, 2011; pp. 1135-1142. Available online: http:/ /www.formatex.info/ microbiology3/book/1135-1142.pdf (accessed on 4 January 2017).

19. Yaouba, A.; Tatsadjieu, N.L.; Michel, J.D.P.; Etoa, F.X.; Mbofung, C.M. Antifungal properties of essential oils and some constituents to reduce foodborne pathogen. J. Yeast Fungal Res. 2010, 1, 1-8.

20. Scalbert, A.; Monties, B.; Janin, G. Tannins in wood-comparison of different estimation methods. Agric. Food Chem. 1989, 37, 1324-1329. [CrossRef]

21. Standard NF ISO 14715. Huile Essentielle de thym à Thymol, Type Espagne (Thymus zygis (Loefl.) L.). Available online: http:/ /agris.fao.org/agris-search/search.do?recordID=XF2016044187 (accessed on 4 January 2017).

22. Standard NF ISO 855. Huile Essentielle de Citron (Citrus limon (L.) Burm. F.), Obtenue par Expression. 2004. Available online: https://www.boutique.afnor.org/norme/nf-iso-855/huile-essentielle-de-citron-citruslimon-l-burm-f-obtenue-par-expression/article/655942/fa102658 (accessed on 5 January 2017).

23. Standard NF ISO 1342. Huile Essentielle de Rosmarin (Rosmarinus officinalis L.). 2012. Available online: https://www.boutique.afnor.org/norme/nf-iso-1342/huile-essentielle-de-romarin-rosmarinus-officinalis-1/ article/667940/fa169820 (accessed on 5 January 2017).

24. Standard NF ISO 3141. Huile Essentielle de Feuilles de Giroflier [Syzygium aromaticum. (L.) Merr. et Perry, syn. Eugenia caryophyllus (Sprengel) Bullock et S. Harrison]. 1997. Available online: http:/ /www.iso.org/ iso/fr/home/store/catalogue_tc/catalogue_detail.htm?csnumber=8310 (accessed on 5 January 2017).

25. Standard NF ISO 4730. Confirmed in 2012 Oil of Melaleuca, terpinen-4-ol Type (Tea Tree Oil). 2004. Available online: https:/ /www.iso.org/obp/ui/\#iso:std:iso:4730:ed-2:v1:en (accessed on 5 January 2017).

26. D'Acampora Zellner, B.; Dugo, P.; Dugo, G.; Mondello, L. Analysis of Essential Oils. In Handbook of Essential Oils: Science, Technology, and Applications; Baser, K.H.C., Buchbauer, G., Eds.; CRC/Taylor \& Francis: Boca Raton, FL, USA, 2010; Chapter 6, pp. 151-185. Available online: https://ttngmai.files.wordpress.com/ 2012/09/handbookofessentionaloil.pdf (accessed on 5 January 2017).

27. Bentayeb, K.; Vera, P.; Rubio, C.; Nerín, C. The additive properties of Oxygen Radical Absorbance Capacity (ORAC) assay: The case of essential oils. Food Chem. 2014, 148, 204-208. [CrossRef] [PubMed]

28. Omidbeygi, M.; Barzegar, M.; Hamidi, Z.; Naghdibadi, H. Antifungal activity of thyme, summer savory and clove essential oils against Aspergillus flavus in liquid medium and tomato paste. Food Control 2007, 18, 1518-1523. [CrossRef]

29. Abdollahzadeh, E.; Rezaei, M.; Hosseini, H. Antibacterial activity of plant essential oils and extracts. The role of thyme essential oil, nisin and their combination to control Listeria monocytogenes inoculated in minced fish meat. Food Control 2014, 35, 177-183. [CrossRef]

30. Nowak, A.; Kalemba, D.; Krala, L.; Piotrowska, M.; Czyzowska, A. The effects of thyme (Thymus vulgaris) and rosemary (Rosmarinus officinalis) essential oils on Brochothrix thermosphacta and on the shelf life of beef packaged in high-oxygen modified atmosphere. Food Microbiol. 2012, 32, 212-216. [CrossRef] [PubMed]

31. Bill, M.; Sivakumar, D.; Korsten, L.; Thompson, A.K. The efficacy of combined application of edible coatings and thyme oil in inducing resistance components in avocado (Persea americana Mill.) against anthracnose during post-harvest storage. Crop Prot. 2014, 64, 159-167. [CrossRef] 
32. Stević, T.; Berić, T.; Šavikin, K.; Soković, M.; Gođevac, D.; Dimkić, I.; Stanković, S. Antifungal activity of selected essential oils against fungi isolated from medicinal plant. Ind. Crops Prod. 2014, 55, 116-122. [CrossRef]

33. Goñi, M.G.; Tomadoni, B.; Moreira, M.R.; Roura, S.I. Application of tea tree and clove essential oil on late development stages of Butterhead lettuce. Impact on microbiological quality. LWT Food Sci. Technol. 2013, 54, 107-113. [CrossRef]

34. Shao, X.; Cao, B.; Xu, F.; Xie, S.; Yu, D.; Wang, H. Effect of postharvest application of chitosan combined with clove oil against citrus green mold. Postharvest Biol. Technol. 2015, 99, 37-43. [CrossRef]

35. Sebaaly, C.; Jraij, A.; Fessi, H.; Charcosset, C.; Greige-Gerges, H. Preparation and characterization of clove essential oil loaded liposomes. Food Chem. 2015, 178, 52-62. [CrossRef] [PubMed]

36. Ulei Cuisoare 10 mL FARES-Farmacia Verde-Util21.ro. Available online: http:/ / farmaciaverde.util21.ro/ produs_12853_ulei-cuisoare-10.html (accessed on 4 January 2017).

37. Jiang, Y.; Wu, N.; Fu, Y.-J.; Wang, W.; Luo, M.; Zhao, C.-J.; Zu, Y.-G.; Liu, X.-L. Chemical composition and antimicrobial activity of the essential oil of Rosemary. Environ. Toxicol. Pharmacol. 2011, 32, 63-68. [CrossRef] [PubMed]

38. Barretoa, H.M.; Filhoa, E.C.S.; Limab, E.O.; Coutinhoc, H.D.M.; Morais-Bragac, M.F.B.; Tavaresc, C.C.A.; Tintinoc, S.R.; Regod, J.V.; de Abreue, A.P.L.; Lustosae, M.C.G.; et al. Chemical composition and possible use as adjuvant of the antibiotic therapy of the essential oil of Rosmarinus officinalis L. Ind. Crops Prod. 2014, 59, 290-294. [CrossRef]

39. Bomfim, N.S.; Nakassugi, L.P.; Oliveira, J.F.P.; Kohiyama, C.Y.; Mossini, S.A.G.; Grespan, R.; Nerilo, S.B.; Mallmann, C.A.; Filho, B.A.A.; Machinski, M., Jr. Antifungal activity and inhibition of fumonisin production by Rosmarinus officinalis L. essential oil in Fusarium verticillioides (Sacc.) Nirenberg. Food Chem. 2015, 166, 330-336. [CrossRef] [PubMed]

40. Sánchez-González, L.; González-Martínez, C.; Chiralt, A.; Cháfer, M. Physical and antimicrobial properties of chitosan tea tree essential oil composite films. J. Food Eng. 2010, 98, 443-452. [CrossRef]

41. Kwiecinski, J.; Eick, S.; Wojcika, K. Effects of tea tree Melaleuca alternifolia oil on Staphylococcus aureus in biofilms and stationary growth phase. Int. J. Antimicrob. Agents 2009, 33, 343-347. [CrossRef] [PubMed]

42. Thomsen, N.A.; Hammer, K.A.; Riley, T.V.; Belkum, A.V.; Carson, C.F. Effect of habituation to tea tree (Melaleuca alternifolia) oil on the subsequent susceptibility of Staphylococcus spp. to antimicrobials, triclosan, tea tree oil, terpinen-4-ol and carvacrol. Int. J. Antimicrob. Agents 2013, 41, 343-351. [CrossRef] [PubMed]

43. Shao, X.; Wang, H.; Xu, F.; Cheng, S. Effects and possible mechanisms of tea tree oil vapor treatment on the main disease in postharvest strawberry fruit. Postharvest Biol. Technol. 2013, 77, 94-101. [CrossRef]

44. Ulei Ti-Tree $10 \mathrm{~mL}$ Fares Trading-Farmacia Verde-util21.ro. Available online: http://farmaciaverde.util21. ro/produs_5564_ulei-ti-tree-10ml-fares-trading.html (accessed on 4 January 2017).

45. Li, P.; Zhang, H.; Chen, X.; Qiu, D.; Guo, L. Molecular characterization of a novel hypovirus from the plant pathogenic fungus Fusarium graminearum. Virology 2015, 481, 151-160. [CrossRef] [PubMed]

46. Abbaszadeh, S.; Sharifzadeh, A.; Shokri, H.; Khosravi, A.R.; Abbaszadeh, A. Antifungal efficacy of thymol carvacrol eugenol and menthol as alternative agents to control the growth of food relevant fungi. J. Mycol. Med. 2014, 24, 51-56. [CrossRef] [PubMed]

47. Marın, S.; Velluti, A.; Ramos, A.J.; Sanchis, V. Effect of essential oils on zearalenone and deoxynivalenol production by Fusarium graminearum in non-sterilized maize grain. Food Microbiol. 2004, 21, 313-318. [CrossRef]

48. Varga, J.; Frisvad, J.C.; Kocsubé, S.; Brankovics, B.; Tóth, B.; Szigeti, G.; Samson, R.A. New and revisited species in Aspergillus section. Nigri. Stud. Mycol. 2011, 69, 1-17. [CrossRef] [PubMed]

49. Young, D.G.; Doe, J. Essential Oil Desk Reference, 4th ed.; Life Science Publishing: Lehi, UT, USA, $2007 ;$ p. 360.

50. Ulei Rozmarin 10 mL Fares. Available online: http:/ / farmaciaverde.util21.ro/produs_8996_ulei-rozmarin10.html (accessed on 4 January 2017).

51. Feng, W.; Chen, J.; Zheng, X.; Liu, Q. Thyme oil to control Alternaria alternata in vitro and in vivo as fumigant and contact treatments. Food Control 2011, 22, 78-81. [CrossRef]

52. Rajkovic, K.; Pekmezovic, M.; Barac, A.; Nikodinovic-Runic, J.; Arsenijević, V.A. Inhibitory effect of thyme and cinnamon essential oils on Aspergillus flavus: Optimization and activity prediction model development. Ind. Crops Prod. 2015, 65, 7-13. [CrossRef] 
53. Zhang, Y.; Liu, X.; Wang, Y.; Jiang, P.; Quek, S.Y. Antibacterial activity and mechanism of cinnamon essential oil against Escherichia coli and Staphylococcus aureus. Food Control 2016, 59, 282-289. [CrossRef]

54. Mith, H.; Dure, R.; Delcenserie, V.; Zhiri, A.; Daube, G.; Clinquart, A. Antimicrobial activities of commercial essential oils and their components against food-borne pathogens and food spoilage bacteria. Food. Sci. Nutr. 2014, 2, 403-416. [CrossRef] [PubMed]

55. Proestos, C.; Lytoudi, K.; Mavromelanidou, O.K.; Zoumpoulakis, P.; Sinanoglou, V.J. Antioxidant Capacity of Selected Plant Extracts and Their Essential Oils. Antioxidants 2013, 2, 11-22. [CrossRef] [PubMed]

56. Vasile, C.; Stoleru, E.; Irimia, A.; Zaharescu, T.; Dumitriu, R.P.; Ioanid, G.E.; Munteanu, B.S. Report of the 3-rd RCM Coordinated Research Project: Application of Radiation technology in the Development of Advanced Packaging Materials for Food Products. Chapter 15. Ionizing Radiation and Plasma Discharge Mediating Covalent Linking of Bioactive Compounds onto Polymeric Substrate to Obtain Stratified Composites for Food Packing. Available online: http://www-naweb.iaea.org/napc/iachem/working_materials/F22063\% 20APA416.pdf (accessed on 4 January 2017).

57. Hammer, K.A.; Carson, C.F.; Riley, T.V. Antimicrobial activity of essential oils and other plant extracts. J. Appl. Microbiol. 1999, 86, 985-990. [CrossRef] [PubMed]

58. Janssen, A.M.; Chin, N.L.; Scheffer, J.J.; Baerheim Svendsen, A. Screening for antimicrobial activity of some essential oils by the agar overlay technique. Pharm Weekbl Sci. 1987, 9, 193-197. [CrossRef] [PubMed]

59. Krisch, J.; Tserennadmid, R.; Vágvölgyi, C. Essential oils against yeasts and moulds causing food spoilage. Sci. Against Microb. Pathog. Commun. Curr. Res. Technol. Adv. 2011, 1135-1142.

60. Kacem, N.; Roumy, V.; Duhal, N.; Merouane, F.; Neut, C.; Christen, P.; Hostettmann, K.; Rhouati, S. Chemical composition of the essential oil from Algerian Genista quadriflora Munby and determination of its antibacterial and antifungal activities. Ind. Crops Prod. 2016, 90, 87-93. [CrossRef]

61. Peixoto, L.R.; Rosalen, P.L.; Ferreira, G.L.S.; Freires, I.A.; de Carvalho, F.G.; Castellano, L.R.; de Castro, R.D. Antifungal activity, mode of action and anti-biofilm effects of Laurus nobilis Linnaeus essential oil against Candida spp. Arch. Oral Biol. 2017, 73, 179-185. [CrossRef] [PubMed]

62. Kumar, V.; Mathela, C.S.; Tewari, G.; Singh, D.; Tewari, A.K.; Bisht, K.S. Chemical composition and antifungal activity of essential oils from three Himalayan Erigeron species. LWT Food Sci. Technol. 2014, 56, 278-283. [CrossRef]

63. Frankova, A.; Smid, J.; Bernardos, A.; Finkousova, A.; Marsik, P.; Novotny, D.; Legarova, V.; Pulkrabek, J.; Kloucek, P. The antifungal activity of essential oils in combination with warm air flow against postharvest phytopathogenic fungi in apples. Food Control 2016, 68, 62-68. [CrossRef]

64. Boubaker, H.; Karim, H.; El Hamdaoui, A.; Msanda, F.; Leach, D.; Bombarda, I.; Vanloot, P.; Abbad, A.; Boudyach, E.H.; Aoumar, A.A.B. Chemical characterization and antifungal activities of four Thymus species essential oils against postharvest fungal pathogens of citrus. Ind. Crops Prod. 2016, 86, 95-101. [CrossRef]

65. Tolba, H.; Moghrani, H.; Benelmouffok, A.; Kellou, D.; Maachi, R. Essential oil of Algerian Eucalyptus citriodora: Chemical composition, antifungal activity. J. Mycol. Méd. 2015, 25, e128-e133. [CrossRef] [PubMed]

66. Sharma, A.; Rajendran, S.; Srivastava, A.; Sharma, S.; Kundu, B. Antifungal activities of selected essential oils against Fusarium oxysporum f. sp. lycopersici 1322, with emphasis on Syzygium aromaticum essential oil. J. Biosci. Bioeng. 2016. [CrossRef] [PubMed]

67. Ortez, J.H. Disk Diffusion Testing. In Manual of Antimicrobial Susceptability Testing; Coyle, M.B., Ed.; Antimicrobial Susceptibility Testing. A Self-study Program; American Society of Microbiology: Seattle, WA, USA, 2005; Chapter 4, pp. 39-53.

68. Clinical and Laboratory Standards Institute (CLSI). Performance Standards for Antimicrobial Disk Susceptibility Tests; Approved Standard-11th Edition; CLSI document M02-A11 (ISBN 1-56238-781-2 [Print]; ISBN 1-56238-782-0 [Electronic]); Clinical and Laboratory Standards Institute: Wayne, PA, USA, 2012.

69. Goñi, P.; López, P.; Sánchez-Jarabo, C.; Nerín, C. Antimicrobial activity in the vapour phase of a combination of cinnamon and clove essential oils. Food Chem. 2009, 116, 982-989. [CrossRef]

70. Rubalya Valantina, S.; Neelamegam, P. Selective ABTS and DPPH- radical scavenging activity of peroxide from vegetable oils. Int. Food Res. J. 2015, 22, 289-294. 
71. Lupascu, F.G.; Dragostin, O.M.; Foia, L.; Lupascu, D.; Profire, L. The Synthesis and the Biological Evaluation of New Thiazolidin-4-one Derivatives Containing a Xanthine Moiety. Molecules 2013, 18, 9684-9703. [CrossRef] [PubMed]

72. Stoleru, E.; Munteanu, S.B.; Dumitriu, R.P.; Coroaba, A.; Drobota, M.; Zemljic, F.L.; Pricope, G.M.; Vasile, C. Polyethylene materials with multifunctional surface properties by electrospraying chitosan/vitamin $\mathrm{E}$ formulation destined to biomedical and food packaging applications. Iran Polym. J. 2016, 25, 295-308. [CrossRef]

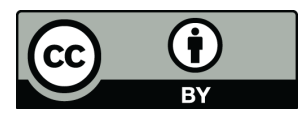

(C) 2017 by the authors; licensee MDPI, Basel, Switzerland. This article is an open access article distributed under the terms and conditions of the Creative Commons Attribution (CC-BY) license (http://creativecommons.org/licenses/by/4.0/). 